\title{
The relationship between screen-based sedentary behaviors and symptoms of depression and anxiety in youth: a systematic review of moderating variables
}

\author{
Jennifer Zink ${ }^{1}$, Britni R. Belcher ${ }^{1 *}$, Kellie $\mathrm{Imm}^{1}$ and Adam M. Leventhal ${ }^{1,2}$
}

\begin{abstract}
Background: To elucidate the populations and conditions where screen-based sedentary behaviors (SB) and internalizing symptoms are coupled, this review synthesized the evidence for factors that may moderate the associations between screen-based SB, depressive symptoms, and anxiety symptoms among youth.

Methods: Two independent researchers conducted a systematic literature search of the Medline, psycINFO, and Scopus electronic databases in late 2018 for observational studies assessing moderators of the association between screen-based SB and depressive and anxiety symptoms. Studies among children and adolescents were eligible if moderation was assessed by statistical test (interaction) or stratification; and a narrative synthesis of eligible studies was conducted in accordance with PRISMA guidelines.

Results: Seventy empirical studies (46 cross-sectional, 19 longitudinal, and 5 both) of 13 different moderating variables of screen-based SB-internalizing symptom associations met the eligibility criteria. Of these, 40 studies were of depressive symptoms, 2 were of anxiety symptoms, and 28 studies assessed symptoms of both. The most consistent evidence of moderation was for screen-type, such that TV viewing was not as strongly associated with internalizing symptoms compared to other forms of screen-based SB. There was also inconsistent evidence for physical activity buffering screen-based SB-internalizing symptom associations and for female sex amplifying screenbased SB-internalizing symptom associations. In general, the body of evidence for anxiety symptoms was more limited than that for depressive symptoms, and were therefore more inconsistent.

Conclusions: Screen-type, physical activity, and sex may influence the magnitude of screen-based SB-internalizing symptom coupling; highlighting potential sources of heterogeneity of screen-based SB-internalizing symptom associations. Additional studies aimed at understanding potential mechanistic explanations for the above moderators are needed prior to the development of tailored intervention strategies designed to decouple screenbased SB and internalizing symptoms among youth.
\end{abstract}

Keywords: Emotional health, Inactivity, Screen time, Digital media, Children, Adolescents

\footnotetext{
* Correspondence: bbelcher@usc.edu

${ }^{1}$ Department of Preventive Medicine, Keck School of Medicine of University

of Southern California, 2001 North Soto Street, Third Floor, California, Los

Angeles 90032, USA

Full list of author information is available at the end of the article
}

C C The Author(s). 2020 Open Access This article is licensed under a Creative Commons Attribution 4.0 International License, which permits use, sharing, adaptation, distribution and reproduction in any medium or format, as long as you give appropriate credit to the original author(s) and the source, provide a link to the Creative Commons licence, and indicate if changes were made. The images or other third party material in this article are included in the article's Creative Commons licence, unless indicated otherwise in a credit line to the material. If material is not included in the article's Creative Commons licence and your intended use is not permitted by statutory regulation or exceeds the permitted use, you will need to obtain permission directly from the copyright holder. To view a copy of this licence, visit http://creativecommons.org/licenses/by/4.0/ The Creative Commons Public Domain Dedication waiver (http://creativecommons.org/publicdomain/zero/1.0/) applies to the data made available in this article, unless otherwise stated in a credit line to the data. 


\section{Introduction}

Screen-based sedentary behaviors (SB) such as television viewing and computer use have become ubiquitous in children and adolescents, in part because of the increasing availability of youth-friendly digital entertainment [1]. Even more concerning, the prevalence of screenbased SB increases across childhood and adolescence [2]. Because screen-based SB are modifiable behaviors that strongly predict future levels of screen-based SB [3] and consequently adverse health-outcomes in adulthood [4], understanding the determinants, correlates, and consequences of screen-based SB among youth is critical for informing preventive interventions that may benefit health throughout the lifespan.

Paralleling the rising rates of screen-based SB, the adolescent developmental period is also a high-risk period for the onset of internalizing symptoms and disorders [5]. Recent national U.S. estimates indicate the lifetime prevalence of depressive or anxiety disorders in adolescents are 11.7 and $31.9 \%$, respectively [6], but the incidence of subclinical depression and anxiety levels is much higher [7, 8]. Depression and anxiety in youth even at levels below the threshold of a psychiatric diagnosis - increase risk for suicide, substance misuse, obesity $[9,10]$, poorer social development, and worse academic performance [11].

Previous systematic reviews and meta-analyses have provided evidence that screen-based SB and internalizing symptoms may be associated with one another among youth [12-14]. It is believed that psychosocial mechanisms play a role in linking screen-based SB and internalizing symptoms. For example, the social withdrawal theory postulates that engaging in screen-based SB can lead to social isolation, which may increase risk for internalizing symptoms [15]. While the abovementioned systematic reviews and meta-analyses were critical for identifying potentially positive associations between screen-based SB and internalizing symptoms, they also highlighted inconsistencies in the findings across the individual studies $[12,14]$. The heterogeneity of findings may, in part, be a result of unexplored moderators of the association between screen-based SB and internalizing symptoms.

A current gap in the literature is the lack of information on potential moderators of the association between screen-based SB and internalizing symptoms that may be contributing to inconsistencies in previous findings. For example, psychosocial factors associated with puberty may lead to the moderation of screen-based SB-internalizing symptom associations by sex such that screen-based SB may be related to depressive symptoms among girls, but not boys [16]. For girls in particular, puberty tends to be a time of high psychological distress, low self-esteem, and body-discontentment [17]. If consistent evidence emerges for sex as a moderator (e.g., screen-based SB-internalizing symptom associations are stronger among girls compared to boys) then heterogeneity across study findings may be attributed, in part, to moderation by sex that previous investigations may have failed to take into account. Overall, identifying the variables that strengthen or weaken the association between screen-based SB and internalizing symptoms is essential to identifying sources of inconsistencies in the existing literature, vulnerable populations, and directions for future research dedicated to optimizing intervention strategies.

Taken together, the goal of this review was to address this literature gap by providing a comprehensive overview and systematically integrate the results of observational studies assessing moderators of screen-based SBdepressive and anxiety symptom associations. Thus, the aims of this paper were to 1) summarize the moderating variables of the association between self-reported screen-based SB (e.g., television viewing, computer use) and depression and anxiety (or depressive and anxiety symptoms) among clinical and nonclinical samples of youth, 2) discuss potential mechanisms of moderation based on the consistency of evidence for particular moderators, and 3) pose suggestions for future research aimed at informing tailored intervention strategies among vulnerable populations.

\section{Methods}

The review was performed in accordance with the Preferred Reporting Items for Systematic Reviews and Meta-Analyses (PRISMA) guidelines [18].

\section{Search strategy}

Until December 2018, JZ and KI separately queried the Medline/PubMed, psycINFO, and Scopus electronic databases using the following search terms: (sedentary OR sitting OR screen time OR media) AND (mental health OR anxiety OR anxious OR depress* OR emotional OR internalizing OR social phobia OR panic disorder) AND (child* OR adolescents OR adolescence OR youth). Titles and abstracts were first evaluated. For those identified as possibly relevant, full texts were retrieved and assessed for inclusion in this review. Reference lists of relevant review articles were also examined.

\section{Study selection criteria}

Peer-reviewed articles reporting on human studies published in English were included. Studies were included if a screen-based SB-anxiety symptom or screen-based SBdepressive symptom association was estimated (or if group differences were tested), and if moderation was investigated by statistically testing interaction terms or by stratifying analyses (e.g., by sex) without a formal statistical test for interaction. In addition, studies that 
reported estimates of associations in a common sample separately across different variants of a construct (e.g., screen-based SB - stratifying analyses by TV viewing, computer use, and videogame playing) were also considered for evidence of moderation. Studies that reported on composite variables comprised of both, screen-based and non-screen-based SB were not included in the current review because screen-based SB-specific associations could not be parsed out. Further, although they may provide specific mechanistic explanations for screen-based SB-internalizing symptom associations, studies that reported on variants within the screen-based SB construct beyond screen-type, such as specific content, were considered outside of the scope of this review. Studies utilizing any measure of anxiety or depressive symptoms, not limited to a clinical diagnosis, and including screening questions were eligible. Disagreement between JZ and KI regarding articles to be included in the review was addressed with discussion until a consensus was met.

\section{Data extraction and evidence synthesis}

Pertinent information from each of the identified fulltext studies was extracted, including authors, year of publication, sample parameters (sample size and mean age), study design, measures of screen-based SB and internalizing symptoms, moderators tested, and study results (parameter estimates) which also included significance of these moderators (amplifier/buffer/null). An amplifier was a stratum of a variable that strengthened the association between screen-based SB and internalizing symptoms, while buffers weakened the strength of the observed relationships. On occasions when a moderator resulted in a significantly protective association between screen-based SB and internalizing symptoms among a particular group and a null association among another group, it was considered as evidence of a buffering effect. For example, if screen-based SB were protective against internalizing symptoms among girls and unrelated to internalizing symptoms among boys, then female sex was considered a buffer. Strata of the same variable that showed comparable associations between screen-based SB and internalizing symptoms were considered null. For example, if analyses were stratified by sex, and both sedentary boys and girls experienced greater odds of depressive symptoms (with highly overlapping confidence intervals), then sex as a moderator was considered null. Percent difference in effect estimates between strata and sample size were also considered when determining the strength of the evidence for moderation on occasions where overlapping confidence intervals were present or when confidence intervals were not provided.
Consistent with previous systematic reviews [19, 20], if $0-33 \%$ of studies of a particular moderating variable provided evidence of significant moderation, then the summary result was classified as null; if $34-59 \%$ of studies of a particular moderating variable provided evidence for significant moderation, then the summary result classified as inconsistent. An inconsistent summary result also occurred in the event that fewer than four individual studies tested a particular variable as a moderator. Lastly, if $60 \%$ or more of studies of a moderating variable provided evidence of significant moderation, then the summary result was classified as significant.

\section{Methodological quality assessment}

$\mathrm{JZ}$ and KI independently rated the methodological quality of each study using a modified version of an eightcomponent rating scale [21], consistent with a previous systematic review of SB and risk for anxiety [22]. Methodological quality was scored based on six components of the abovementioned tool: (1) selection bias (representativeness of the sample), (2) study design (cross-sectional vs. longitudinal), (3) confounders (controlling for demographic characteristics and body mass index), (4) data collection tools (valid and reliable), (5) withdrawals and dropouts (percentage of participants providing full data), and (6) appropriateness of analyses for the study design. The two components from the original were not relevant to observational studies and were therefore not included in our quality assessment were (1) blinding component and (2) other intervention-specific criteria. Each of the six above components were individually rated as weak, moderate, or strong. If a component was not described in enough detail to assign a rating, it was rated as weak. Once all six components of a study were rated, the study was given an overall rating. Studies were rated as (1) weak, if two or more individual components were rated as weak, (2) moderate, if less than three components were rated as strong with no more than one component with a weak rating, or (3) strong, if three or more study components were rated as strong.

\section{Results \\ Overview of the studies}

Figure 1 presents the PRISMA flow of study selection. The initial literature search yielded 1964 articles. After removal of duplicates, 1543 articles remained. After screening titles and abstracts for relevance, 147 full-text articles were retrieved for further review. Seventy fulltext articles tested moderation and were included. Fortysix of these studies were cross-sectional, while 19 were longitudinal, and five were both. Two of these articles assessed anxiety symptoms only, 40 assessed depressive symptoms only, and 28 investigated both internalizing symptoms and their relationship with screen-based SB. 


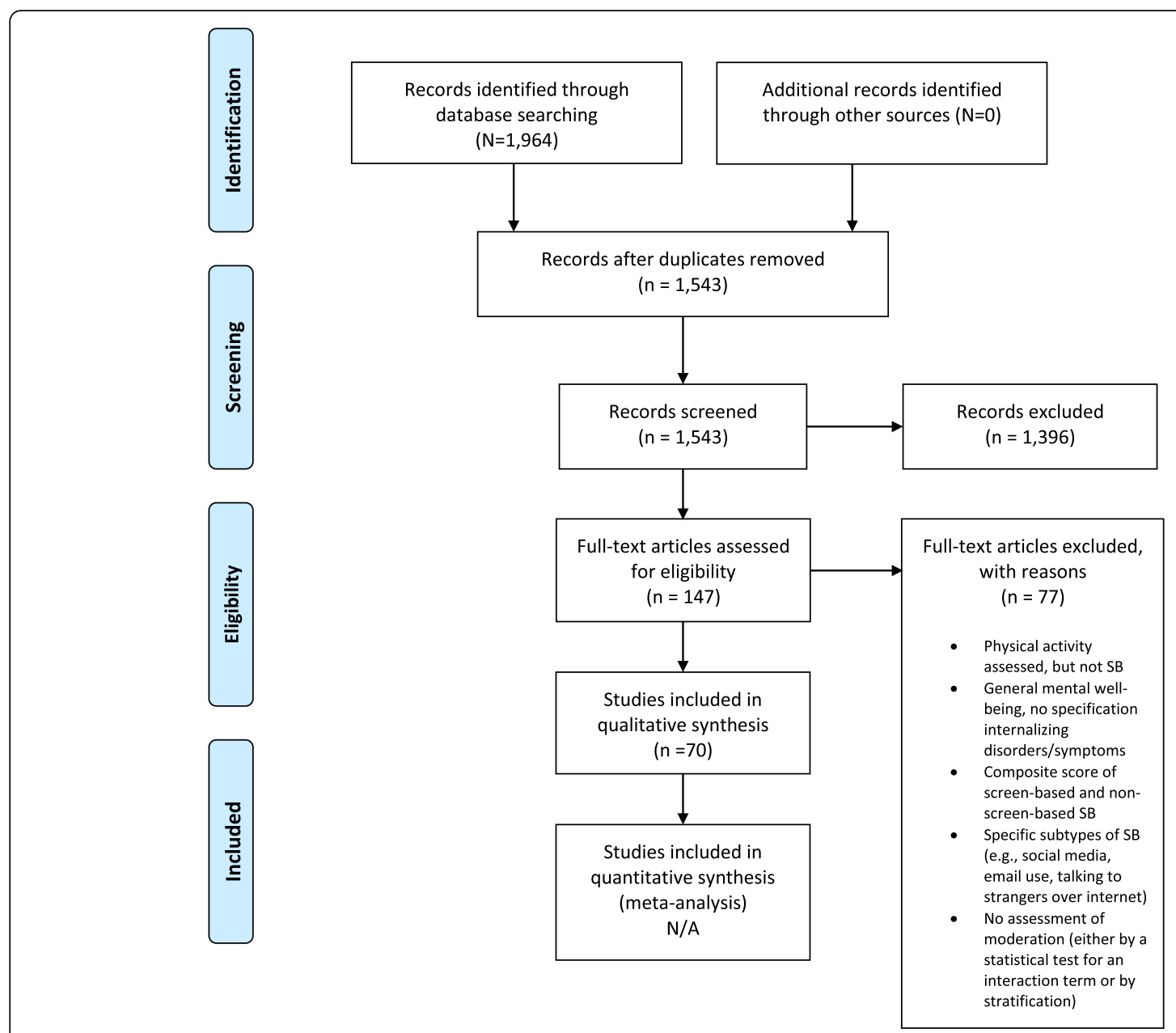

Fig. 1 PRISMA 2009 Flow Diagram of Study Selection

Further, of the 70 studies included in this review, only four were among those with clinical diagnoses of internalizing disorders (as determined by a physician) across three unique samples. Additional characteristics of these studies, including methodological quality score, are presented in Table 1. Interrater reliability (Cohen's Kappa) between JZ and KI regarding manuscripts to be included in the review was 0.77, indicating substantial agreement between raters [91]; there was $80 \%$ agreement on methodological quality scores between raters. The remainder of this section is organized by the moderators that were assessed within the original studies.

Sex (depressive symptoms: $n=43$; anxiety symptoms: $n=20$ ) Forty-three studies tested sex as a moderator when investigating depressive symptom-screen-based SB associations, and of these, approximately half $(n=20)$ provided evidence that sex was a significant moderator. Fourteen (one among a clinical sample) of the 20 studies provided evidence for female sex as an amplifier of screen-based SB-depressive symptom associations $[16,29,39,40,43,52,56,62,69,81,84$, $87,89,90]$. Furthermore, the majority (11 of the 14 , one among a clinical sample) of these studies were conducted in large samples of over 1500 participants, including children and those in early- and mid- adolescence [29, 39, 40, 43, 56, 62, 81, 84, 87, 89, 90]. Only seven studies in adolescents found that female sex acted as a buffer of screen-based SB-depressive symptom associations [36, 46, 50, 67, 73, 82, 83]. Altogether, there is inconsistent evidence $(46.5 \%$ of studies) of moderation of screen-based SB depressive symptom associations by sex; however, among the studies that found sex differences, $70.0 \%$ of studies identified female sex as an amplifier of associations.

Fewer studies $(n=20)$ investigated sex as a moderator of the relationship between screen-based SB and anxiety symptoms. Of the 20 studies, 14 studies did not provide evidence for moderation by sex $[4,23,25,26,45,47,58$, $62,71,72,75,80-82]$. Of the six studies providing evidence for moderation by sex, five (one among a clinical sample and two with samples of over 10,000 participants) 


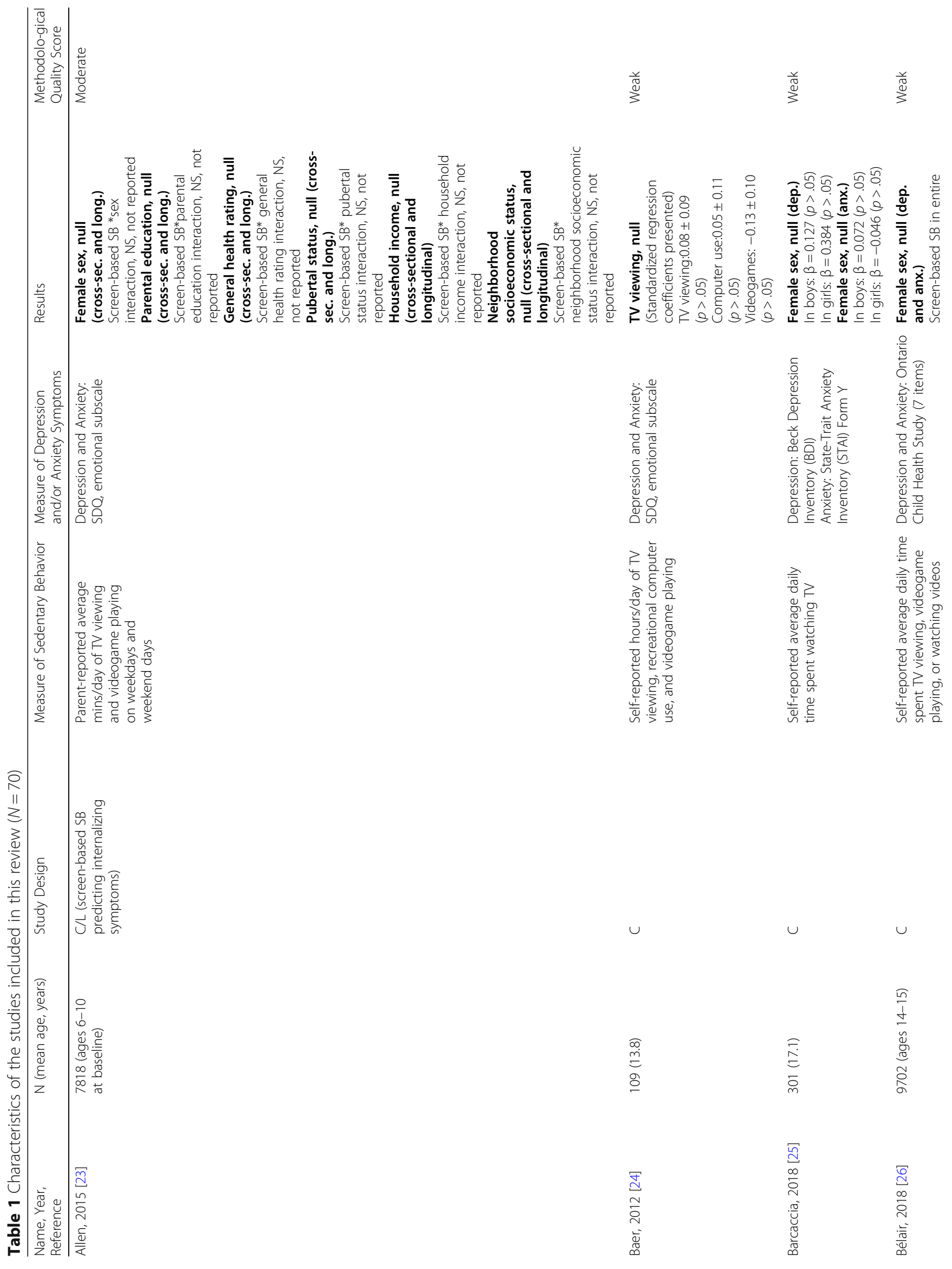




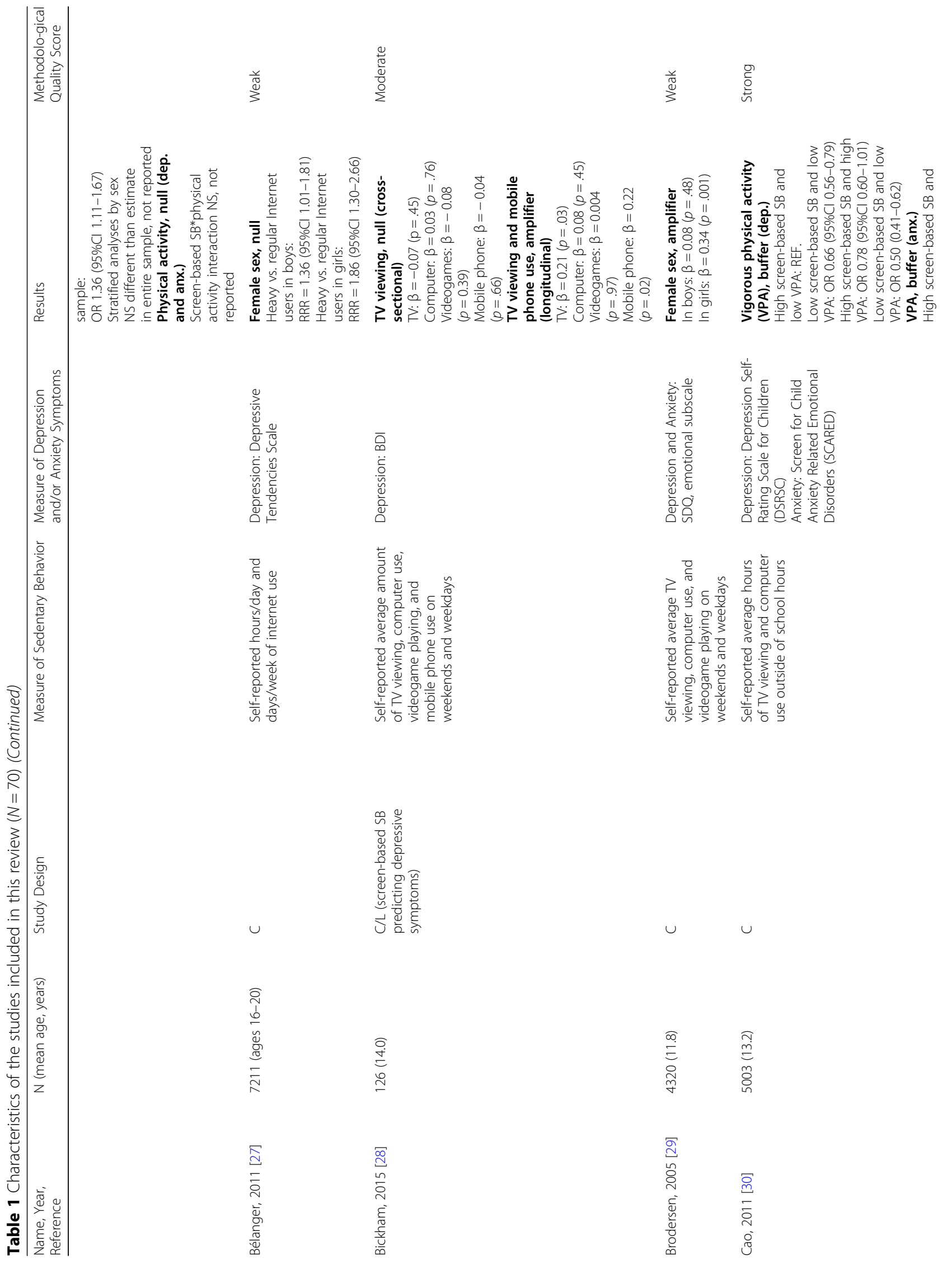




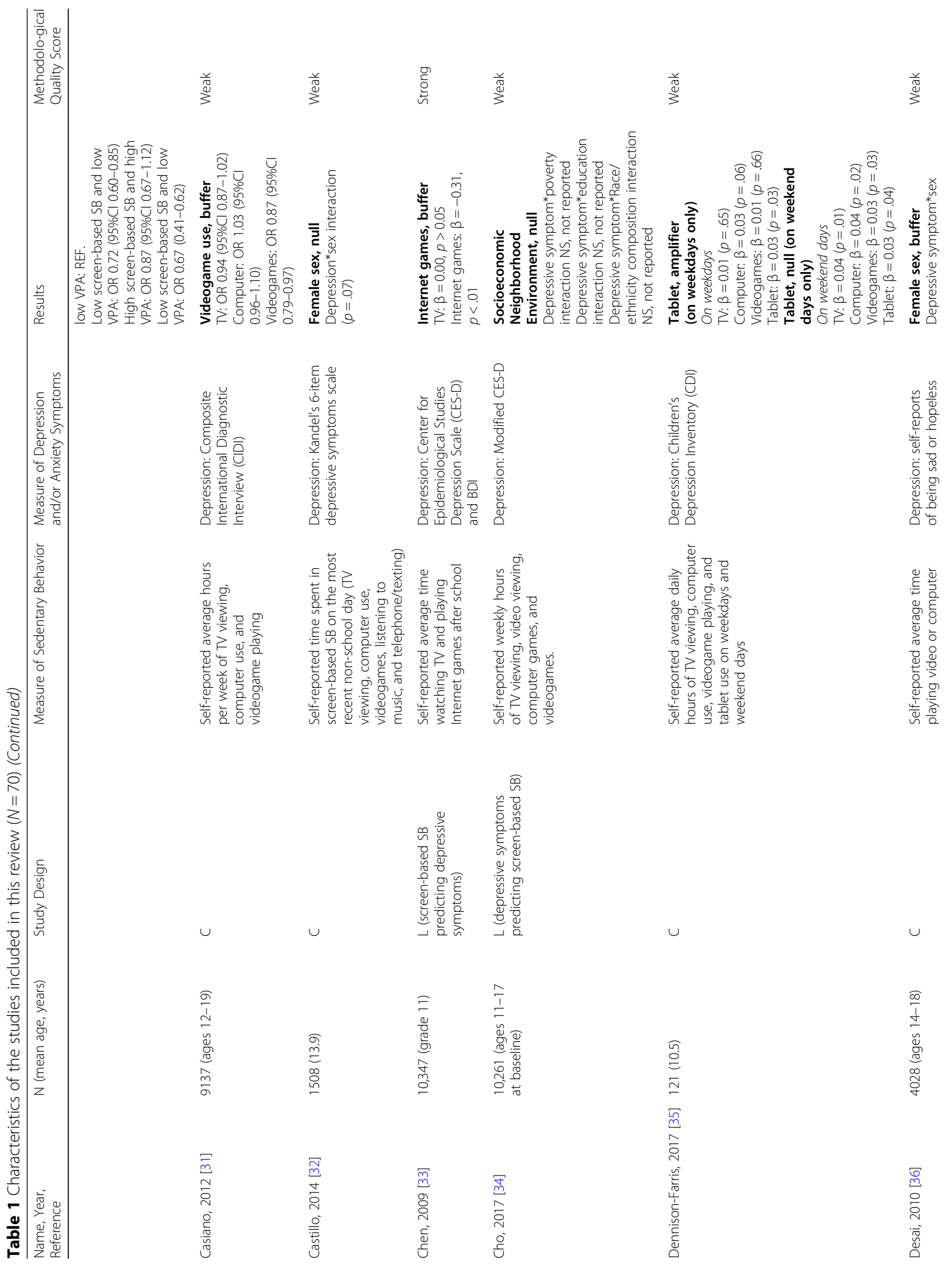




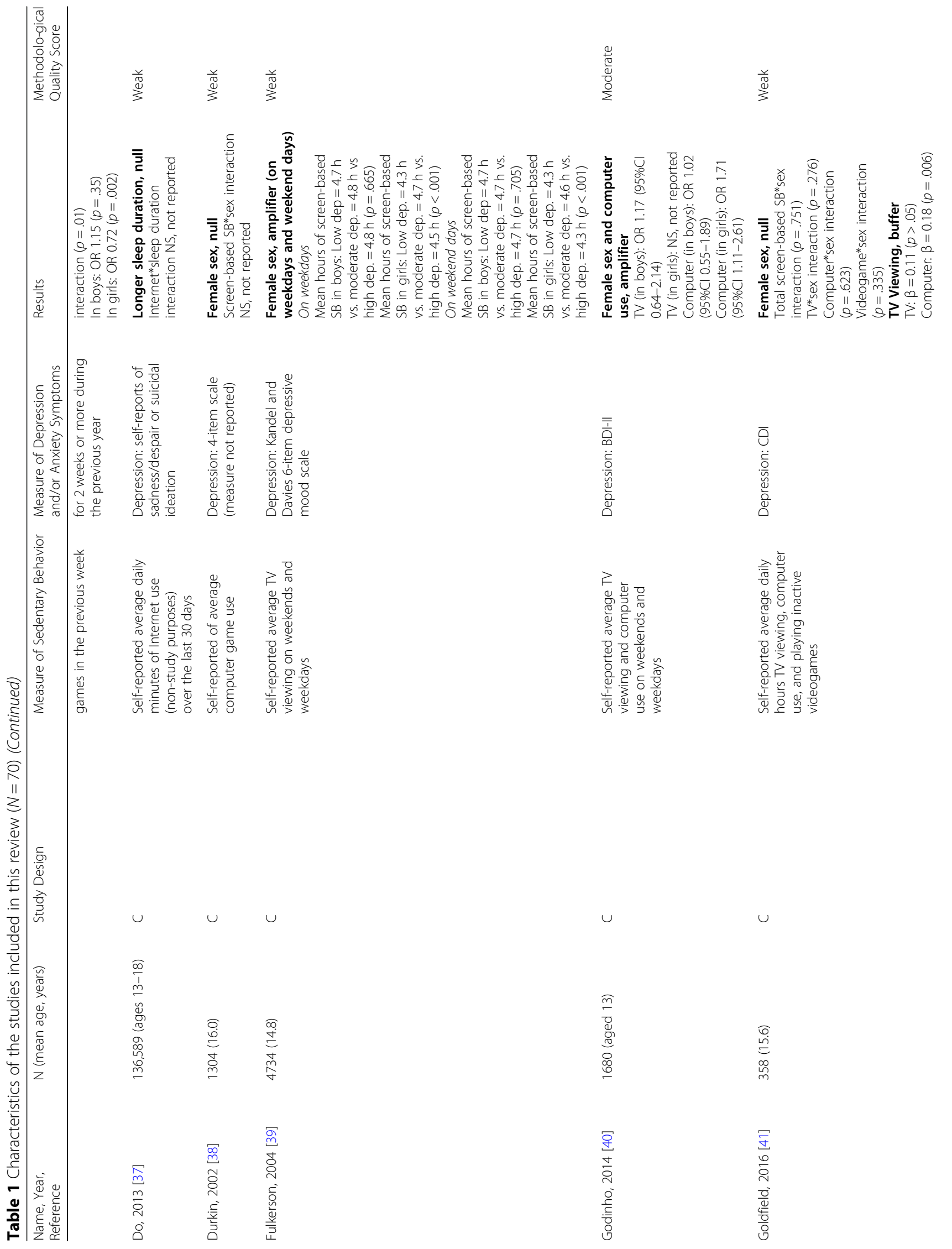




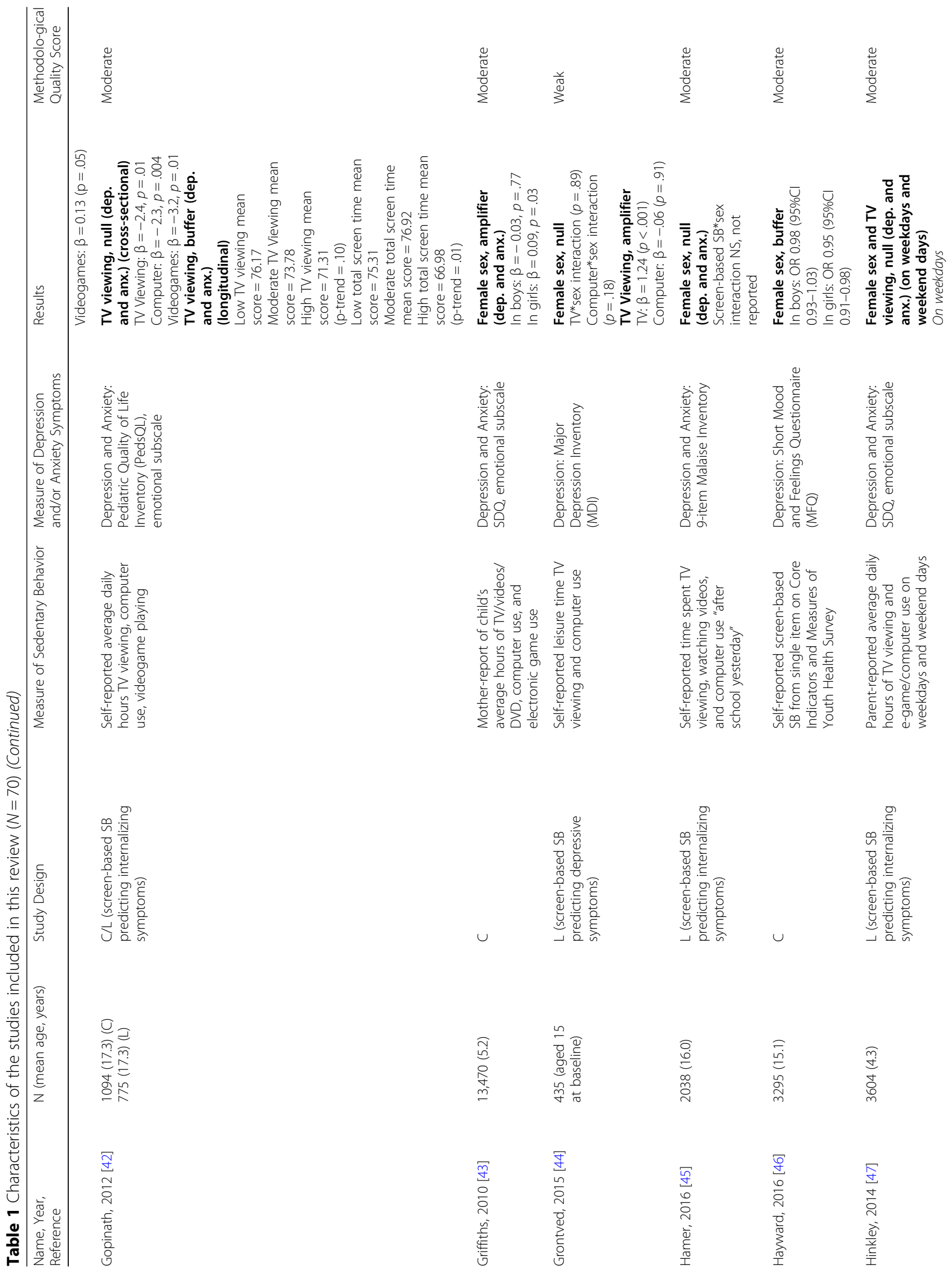




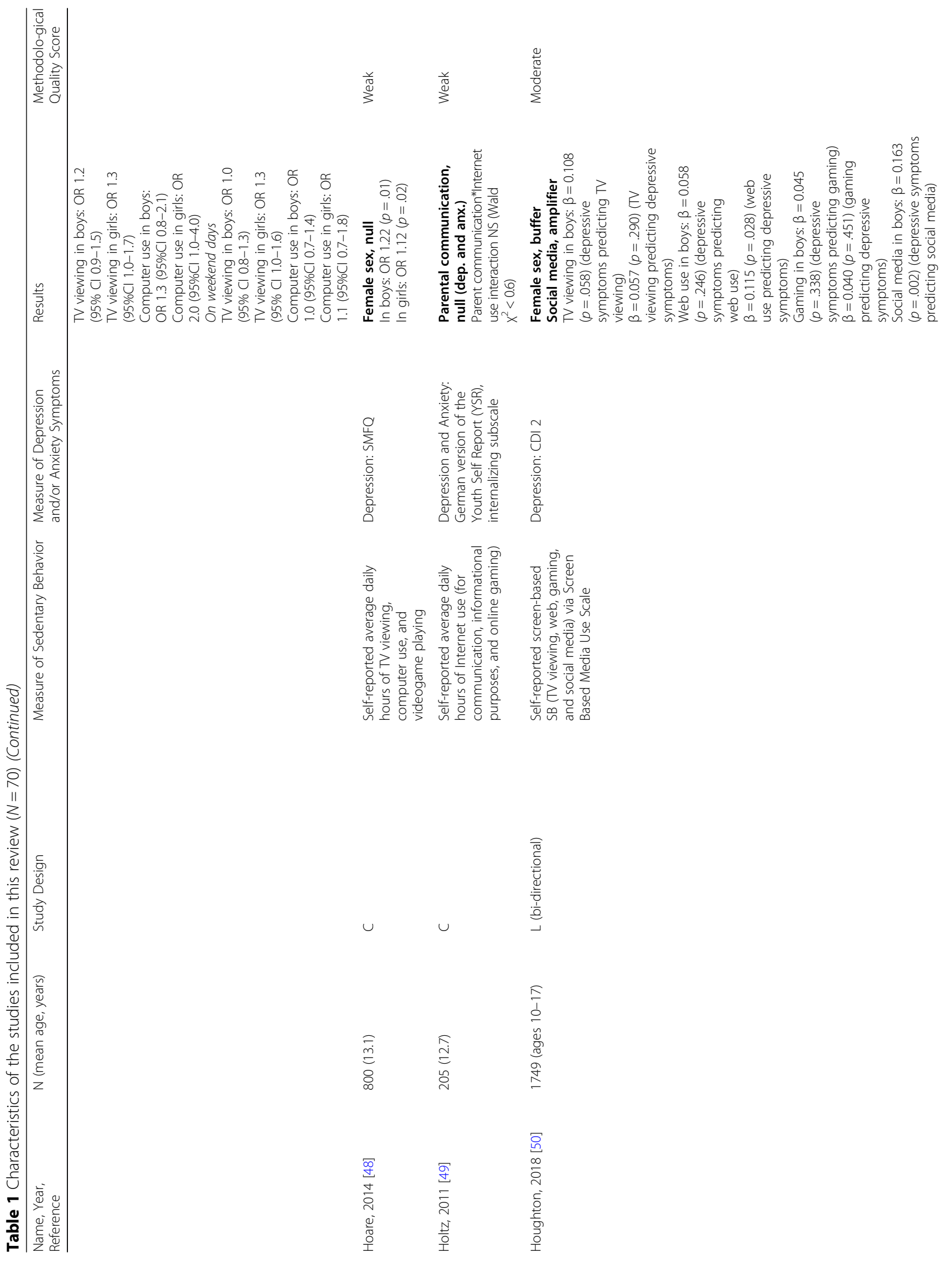




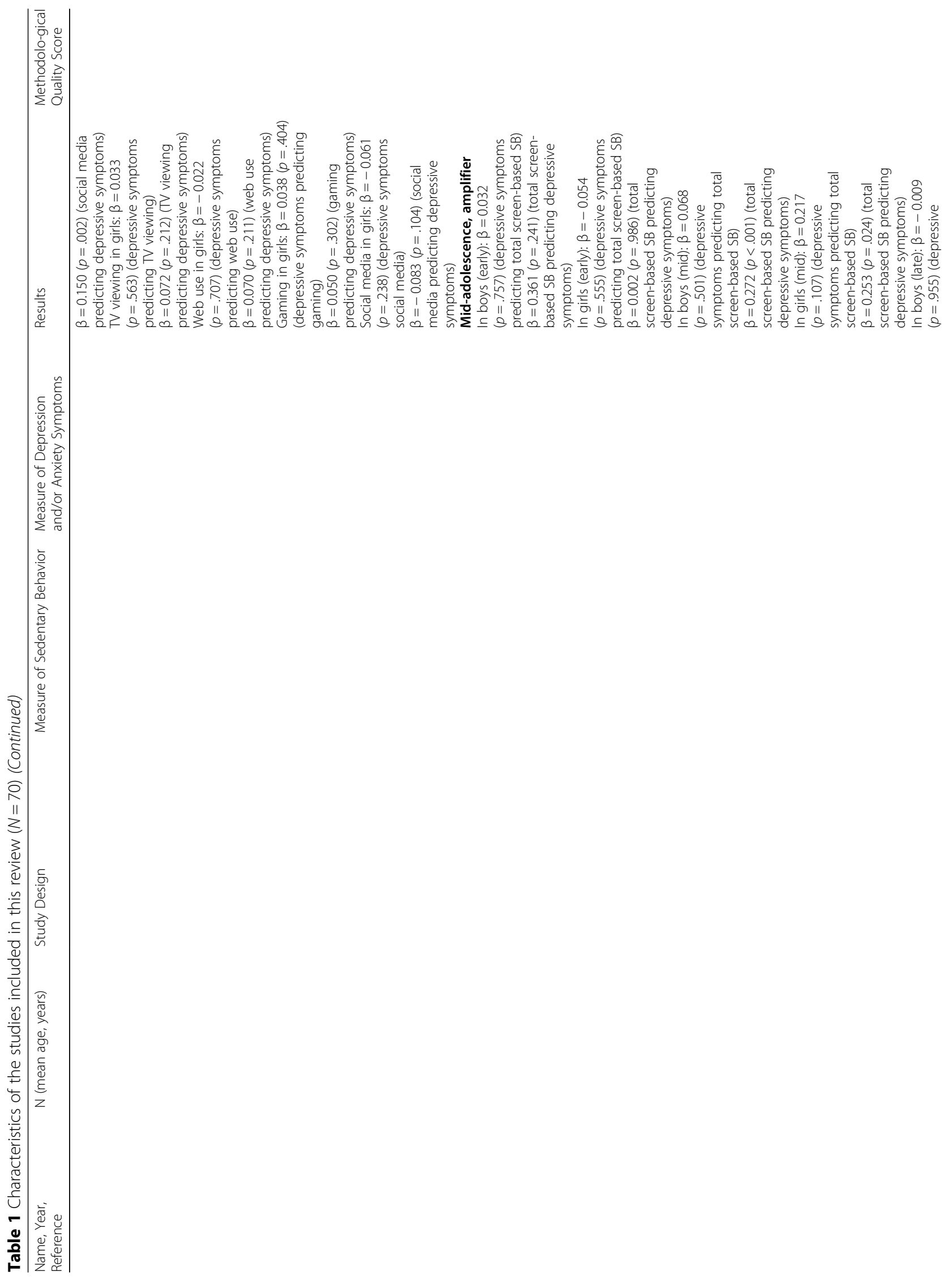




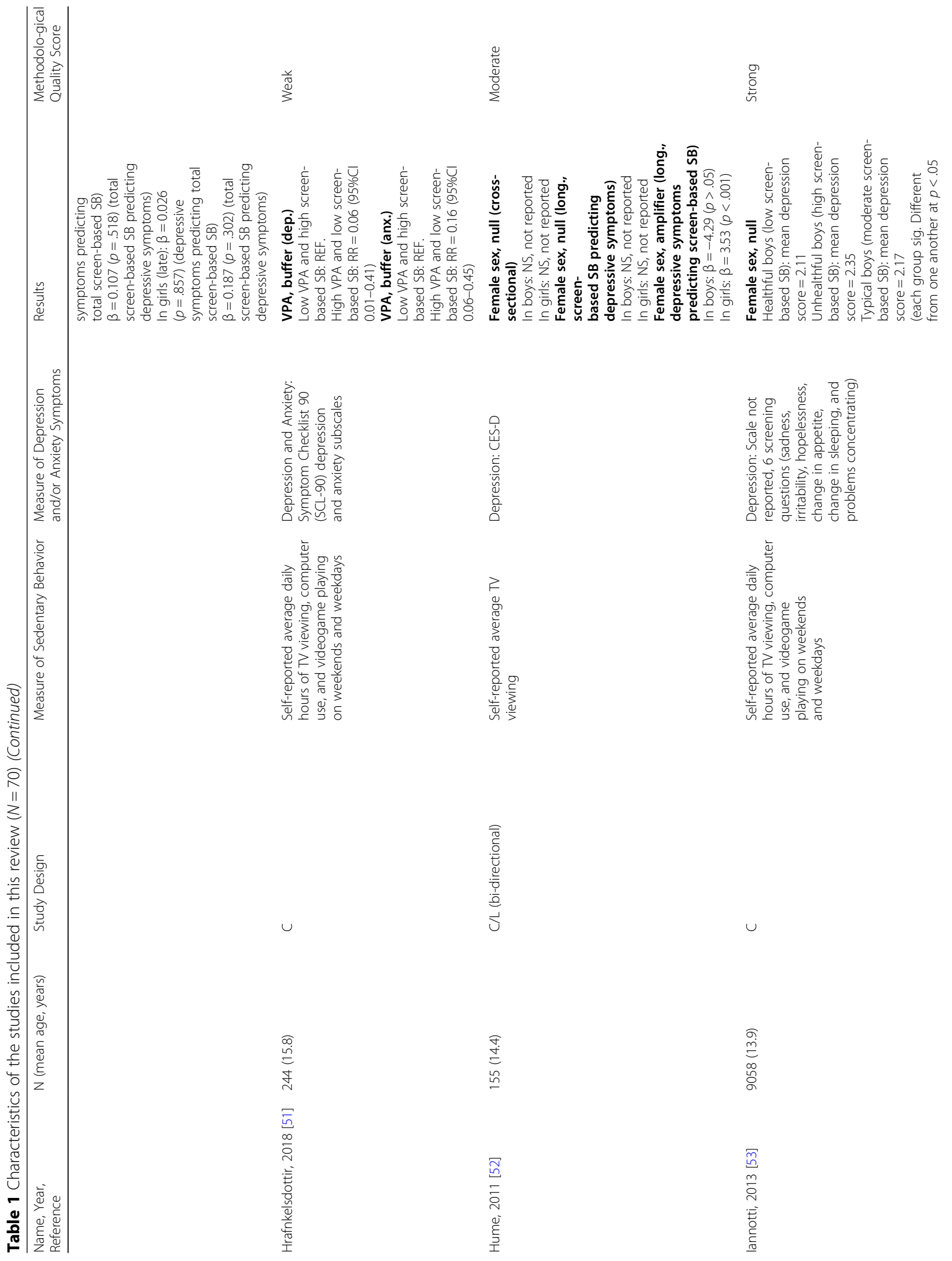




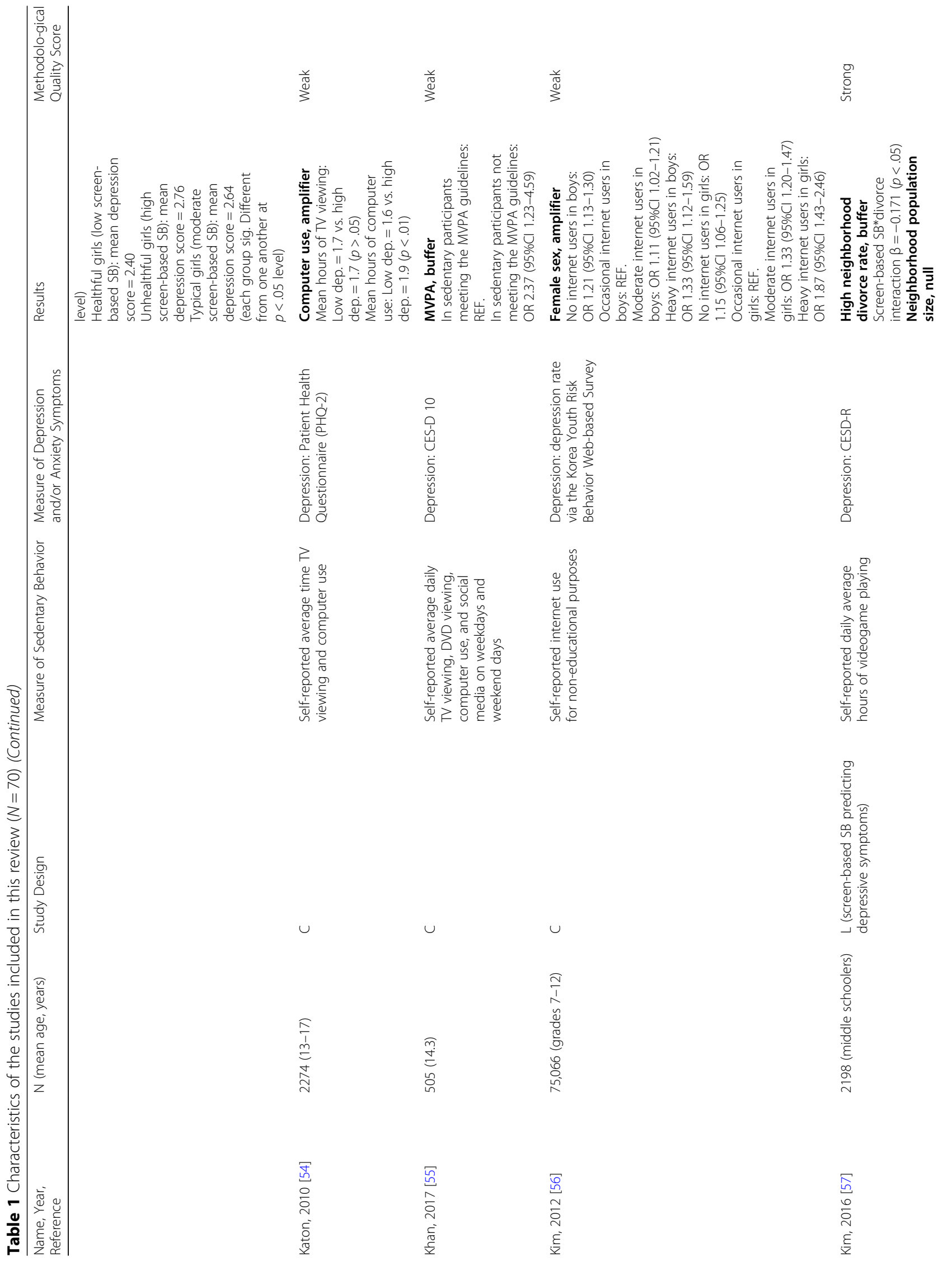




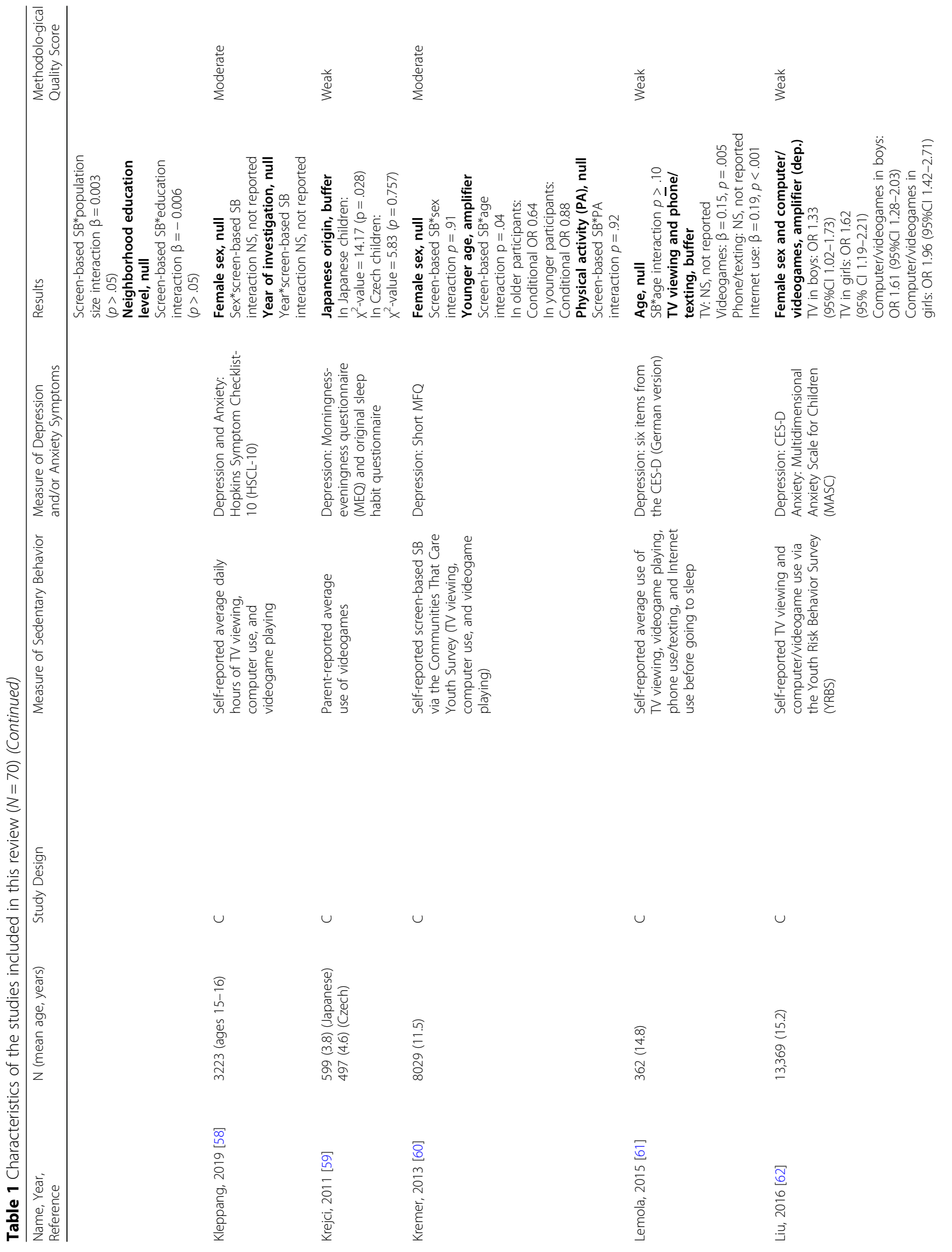




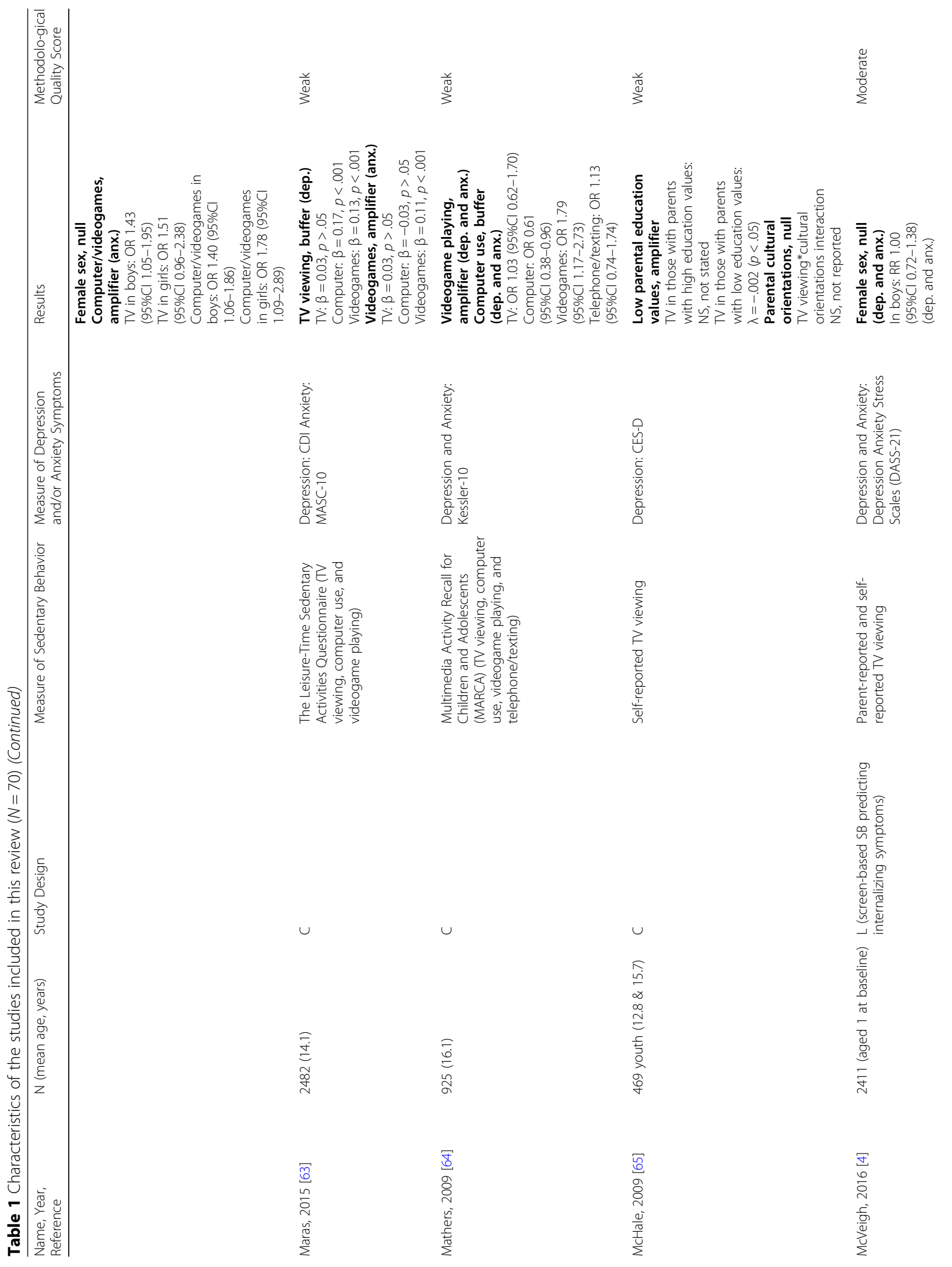




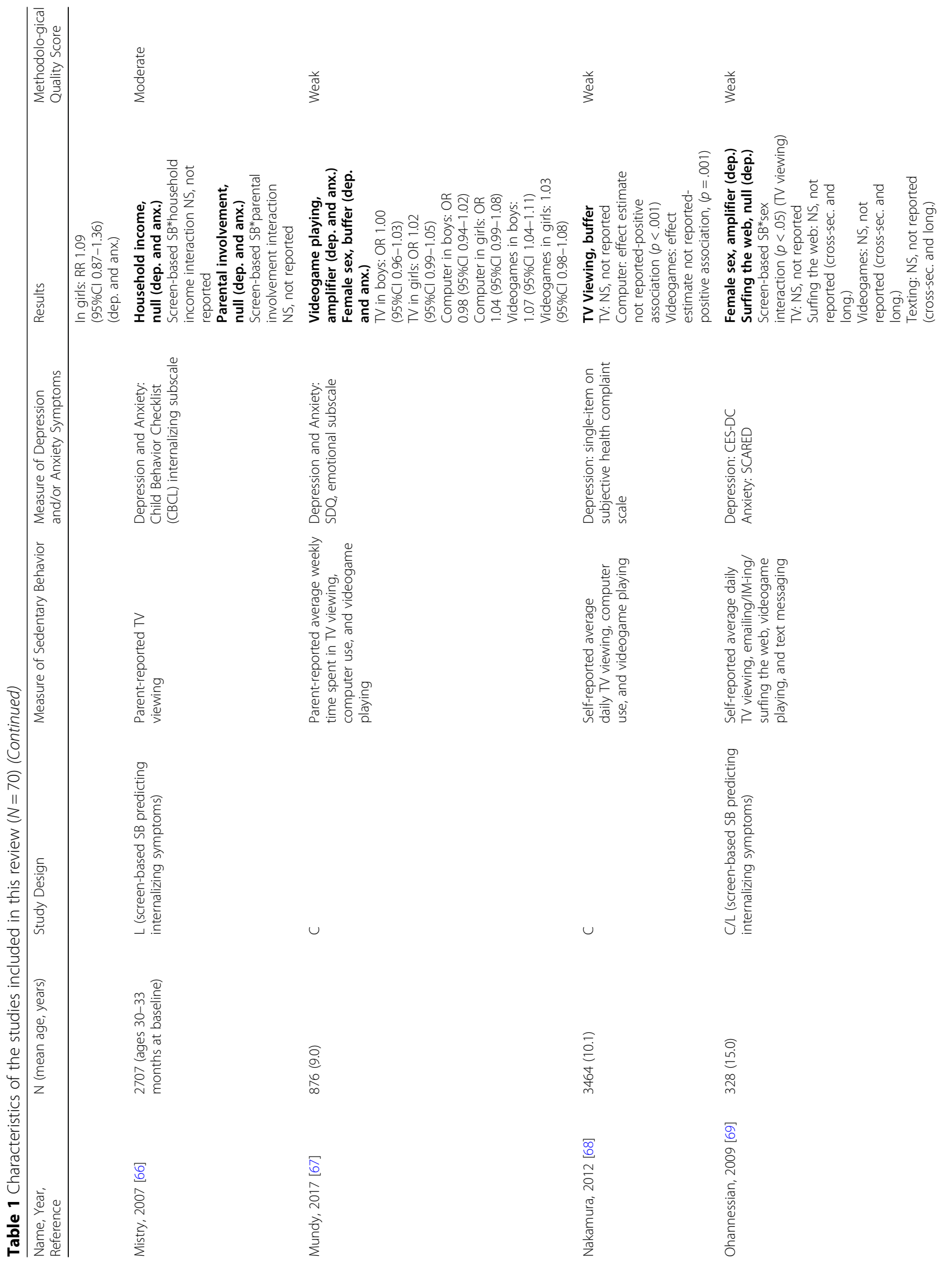




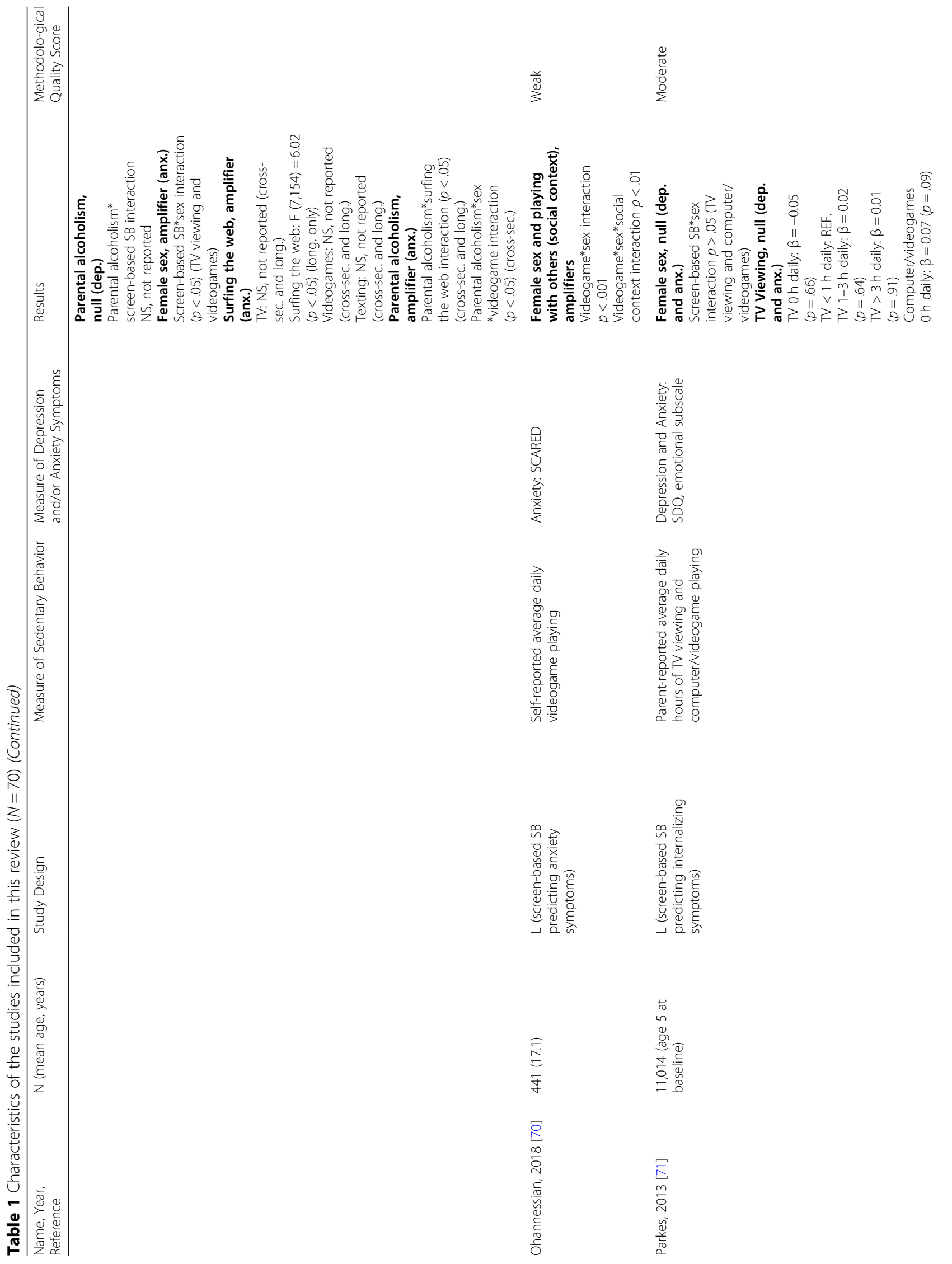




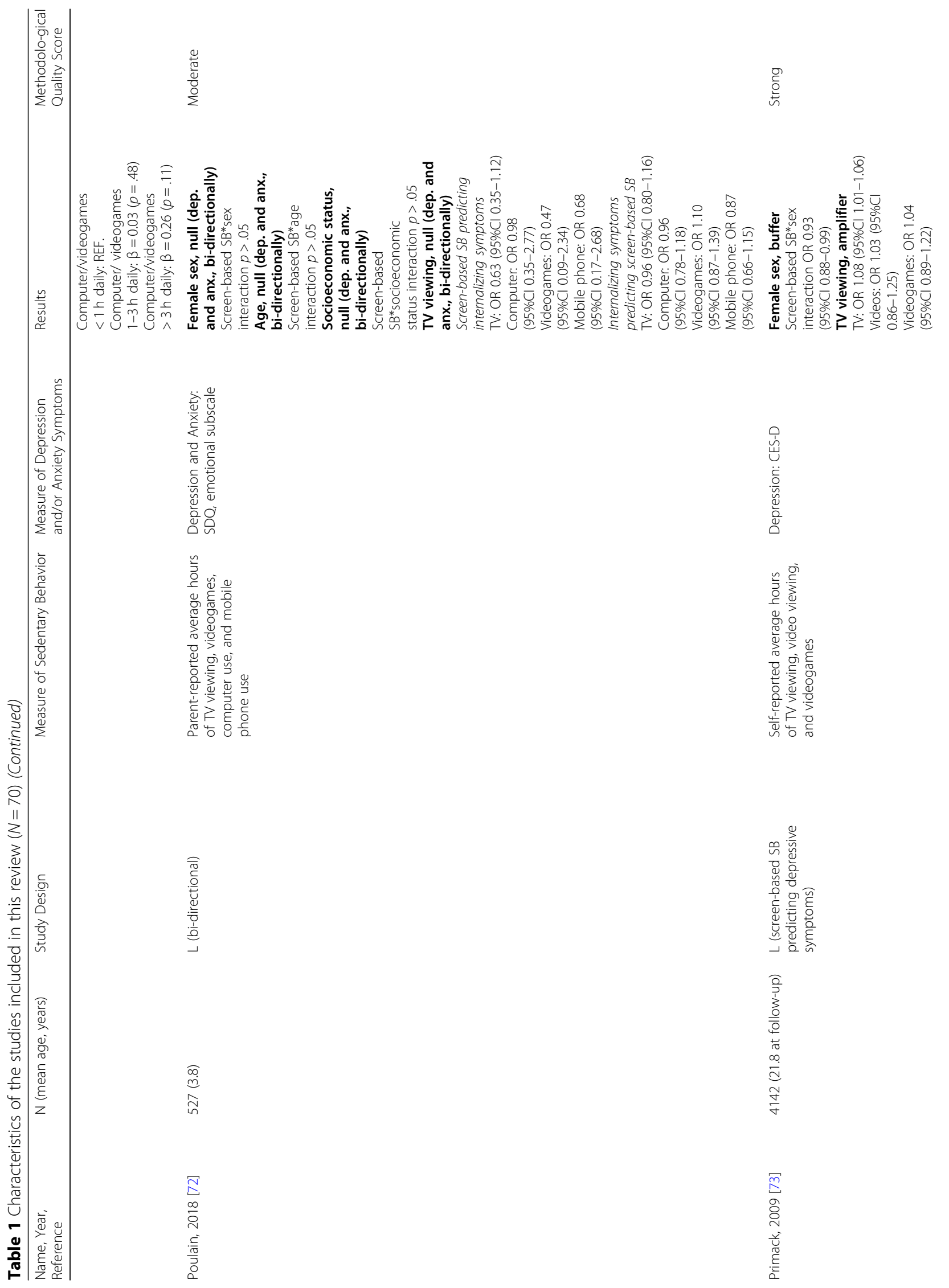




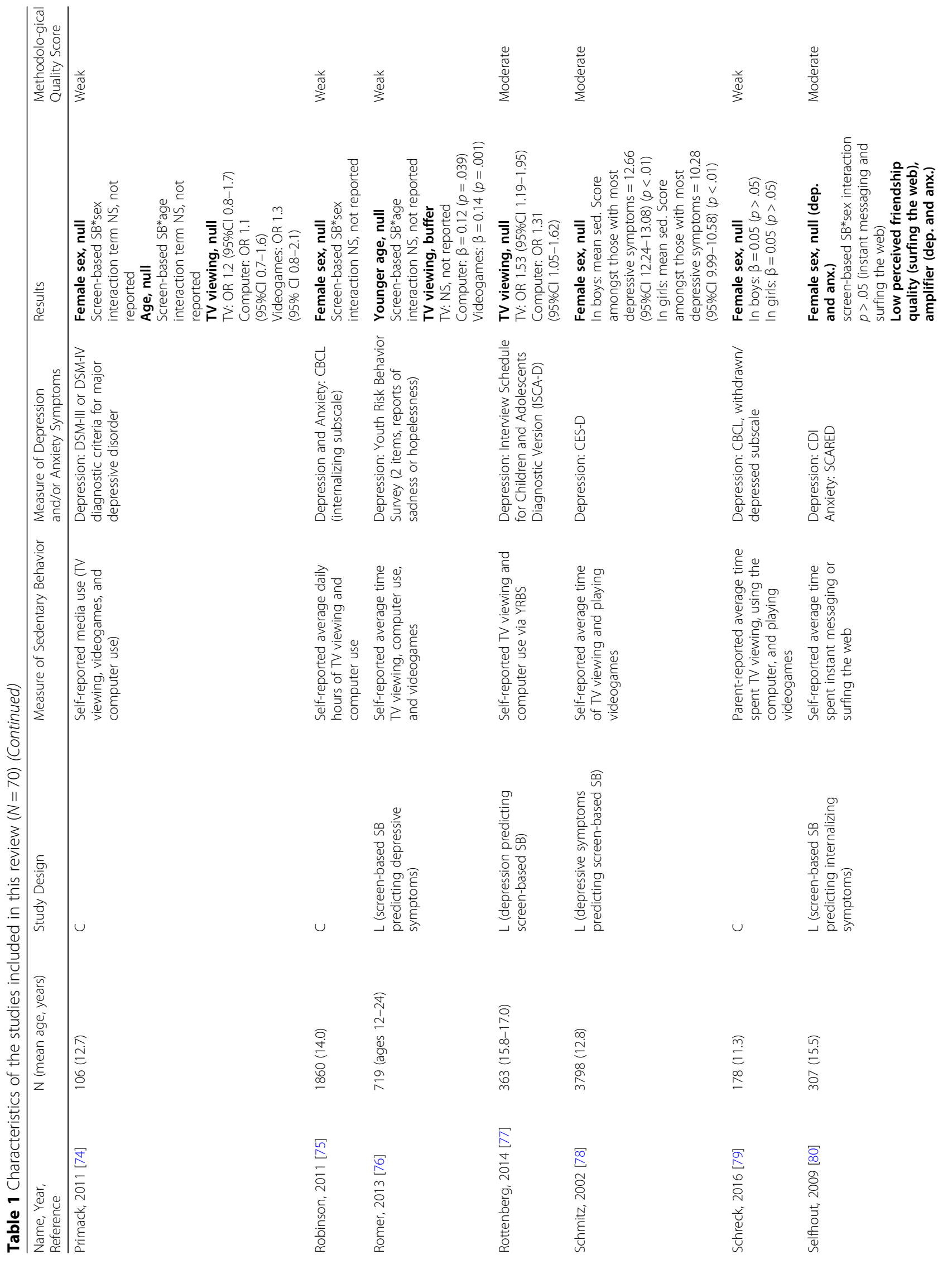




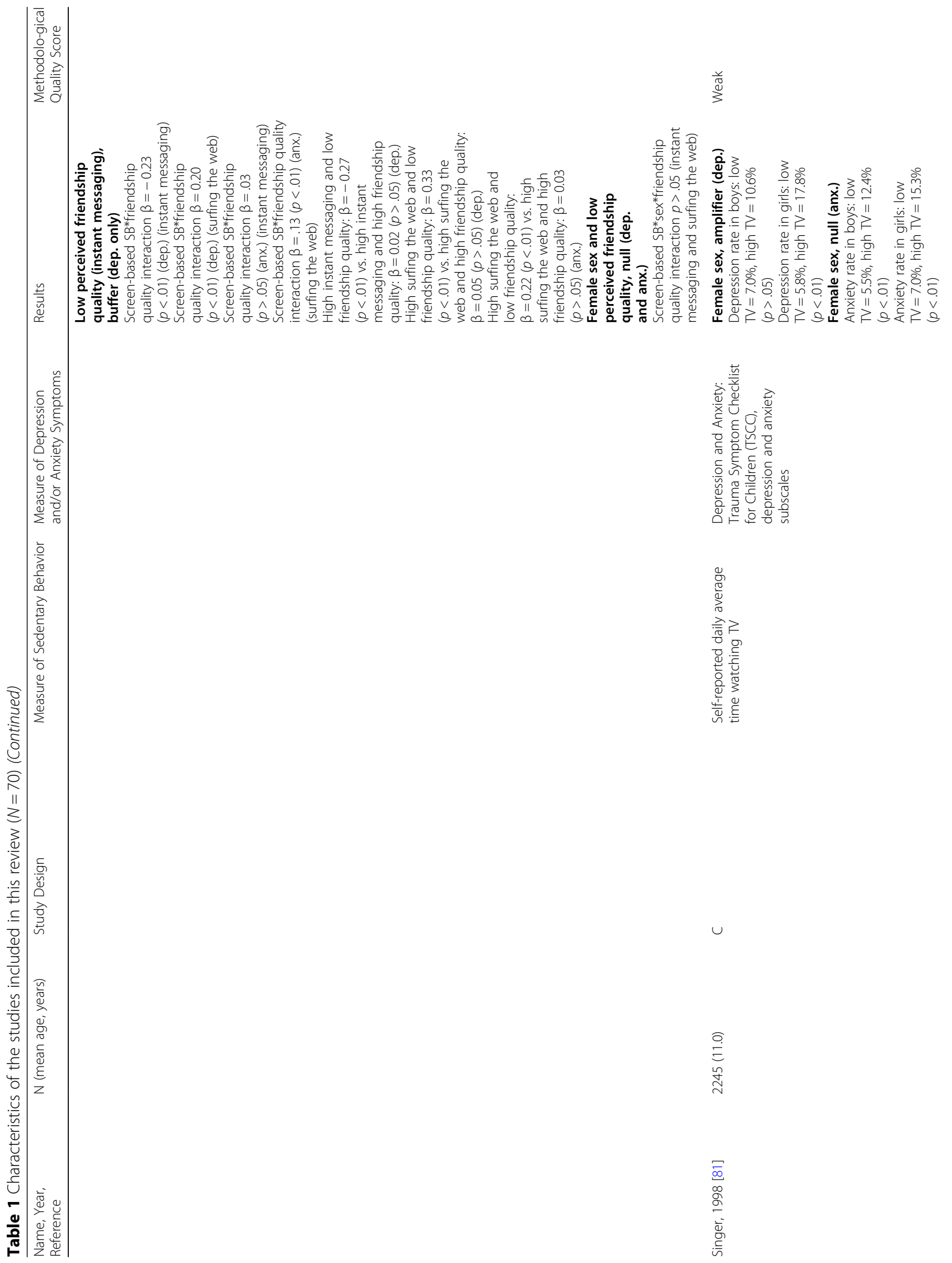




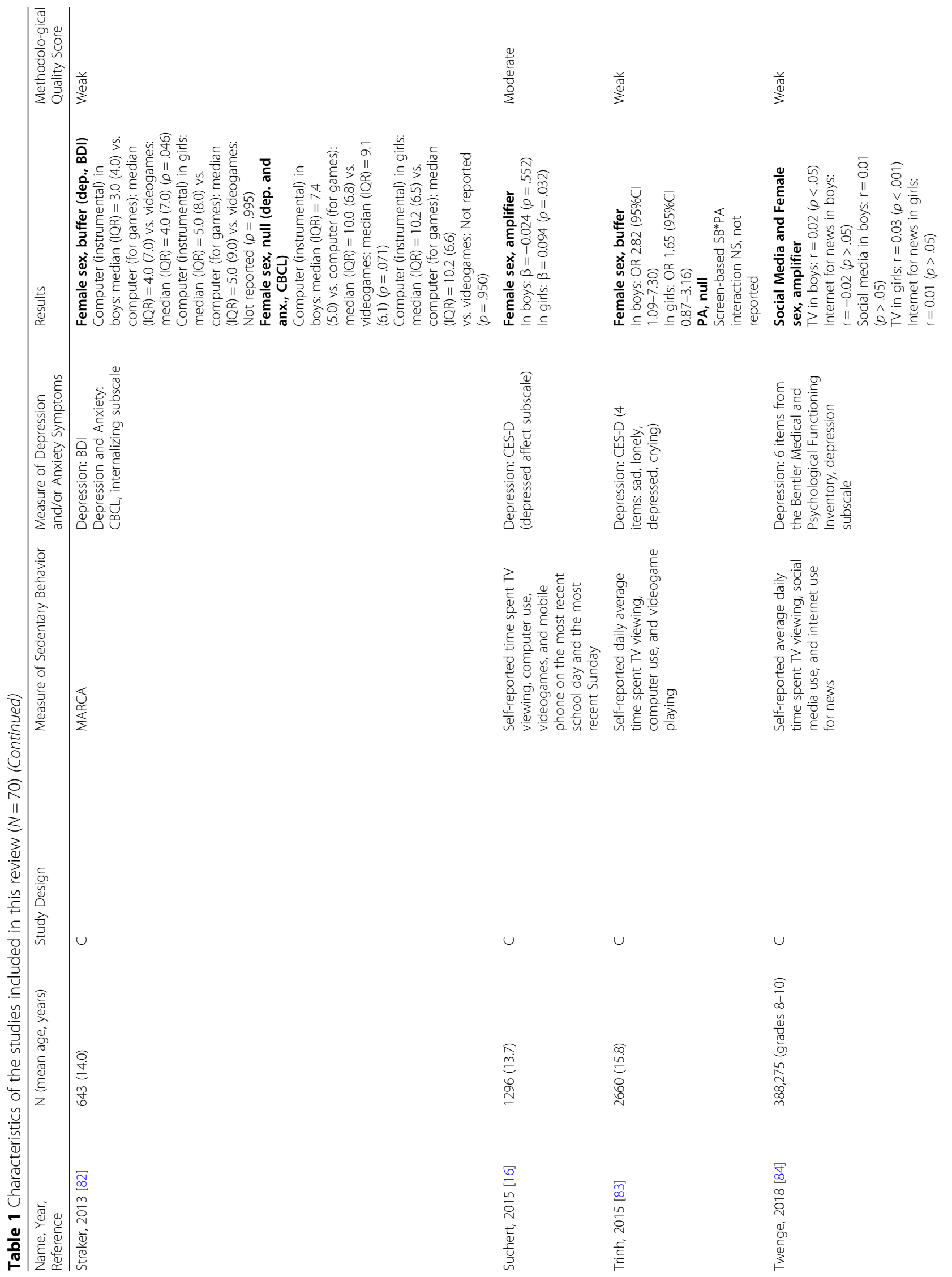




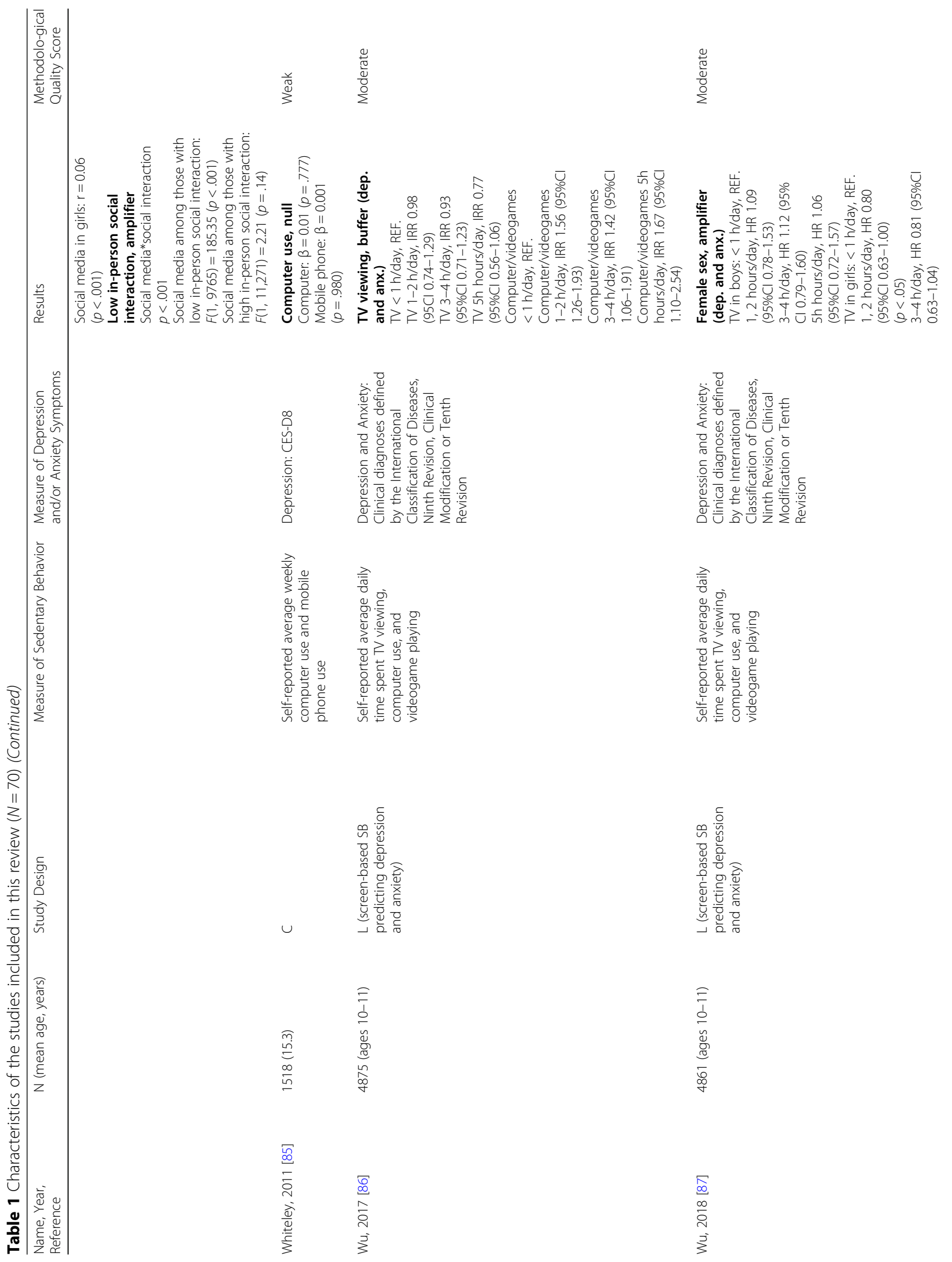




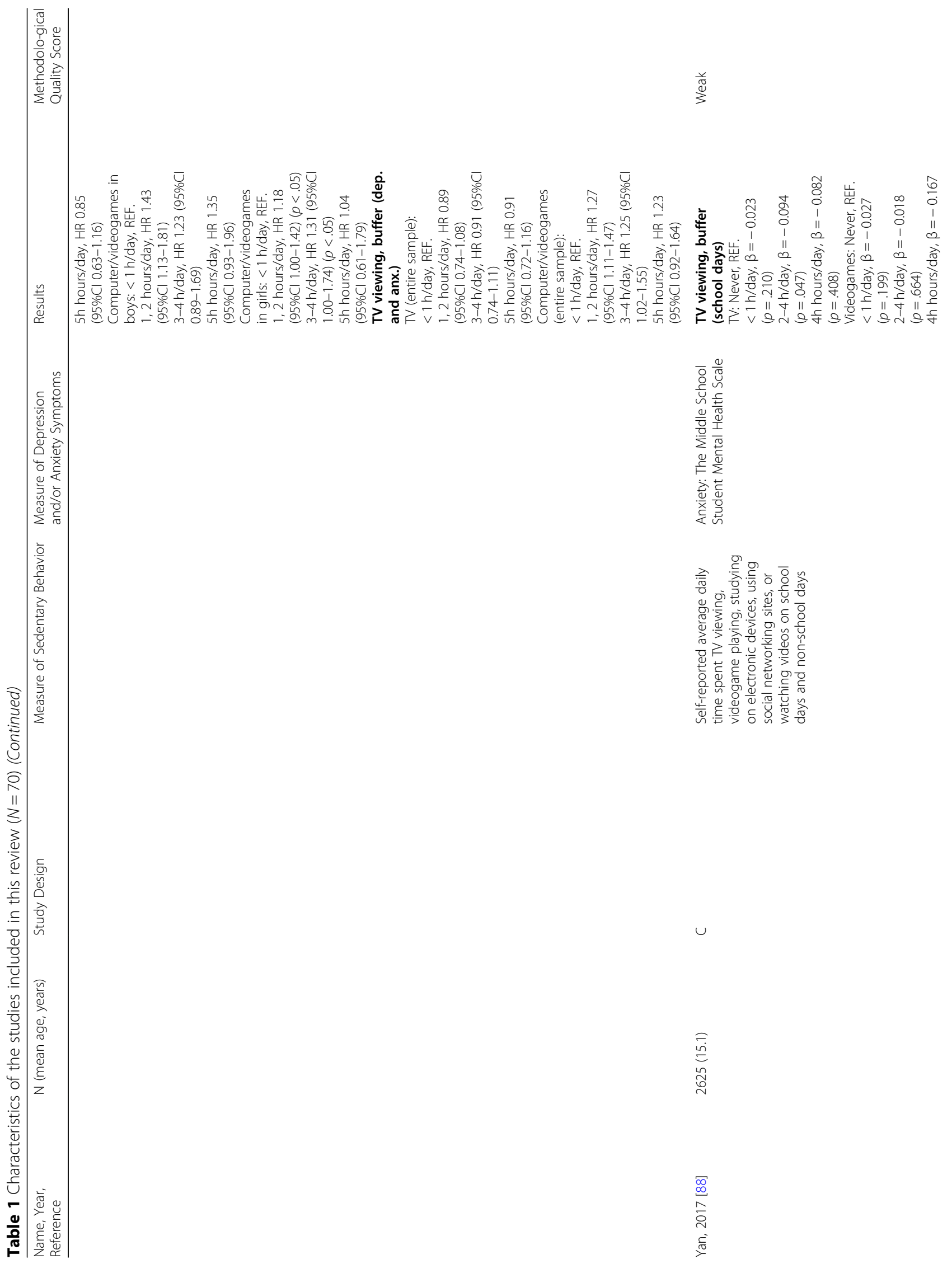




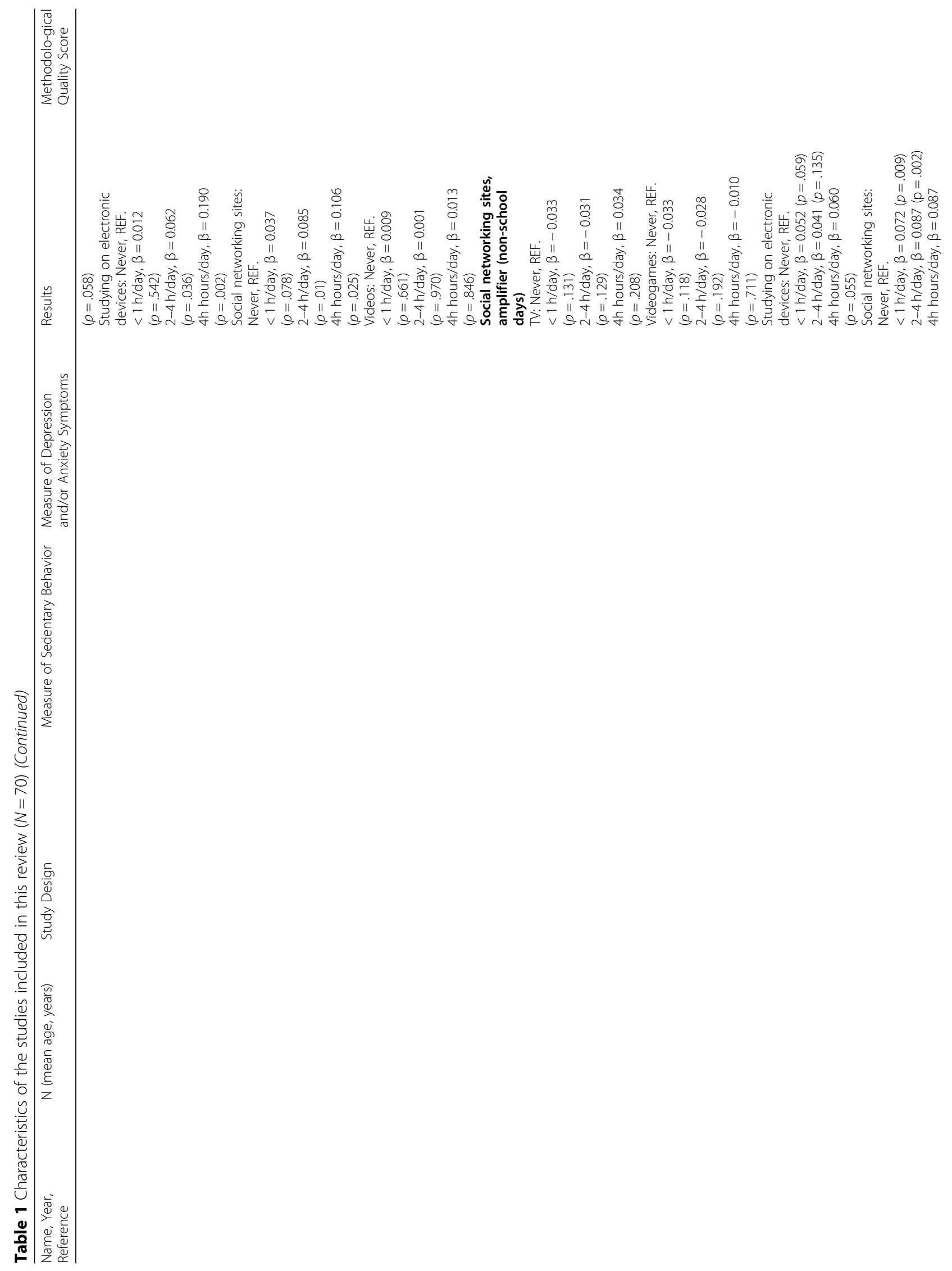




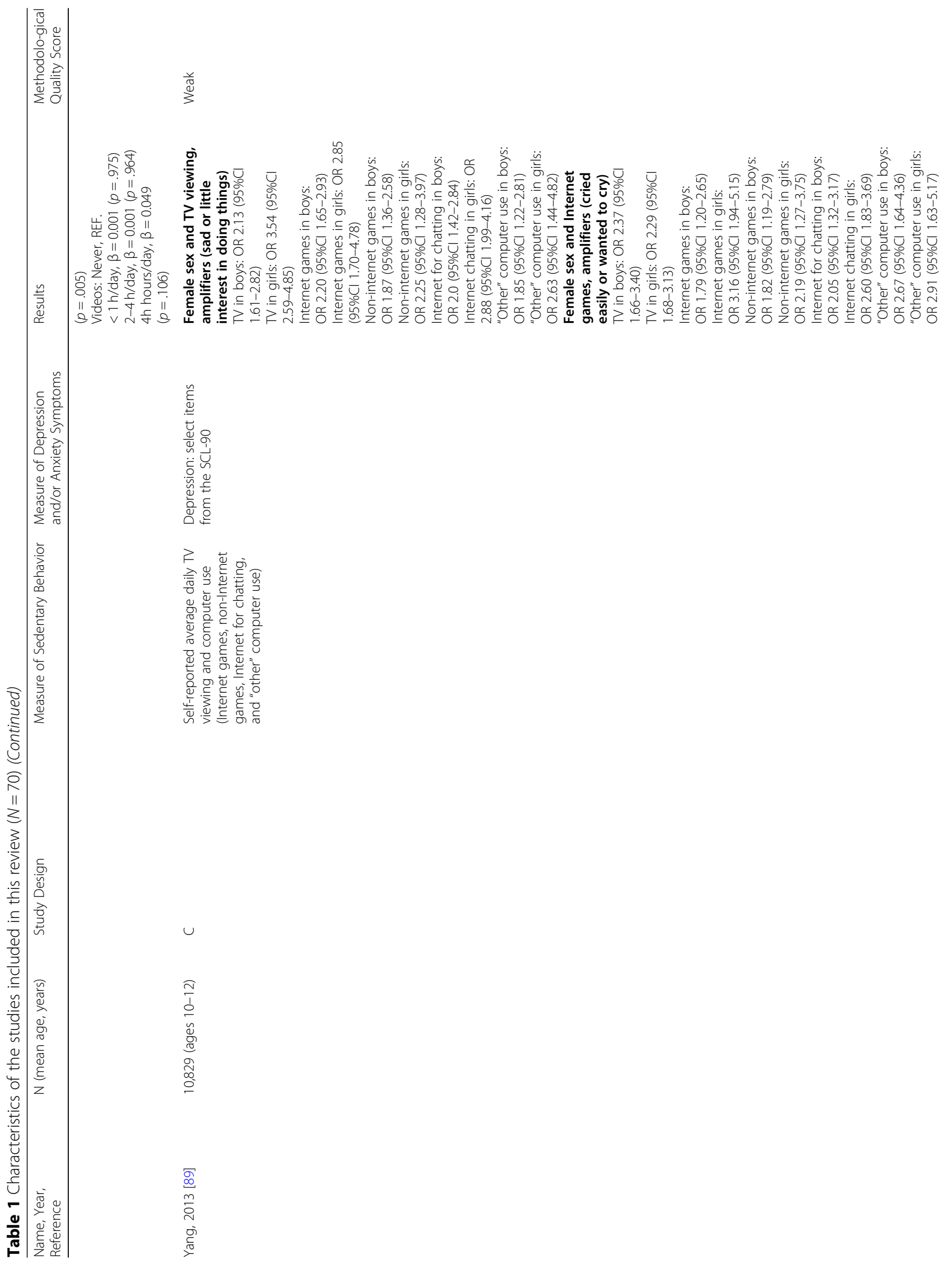




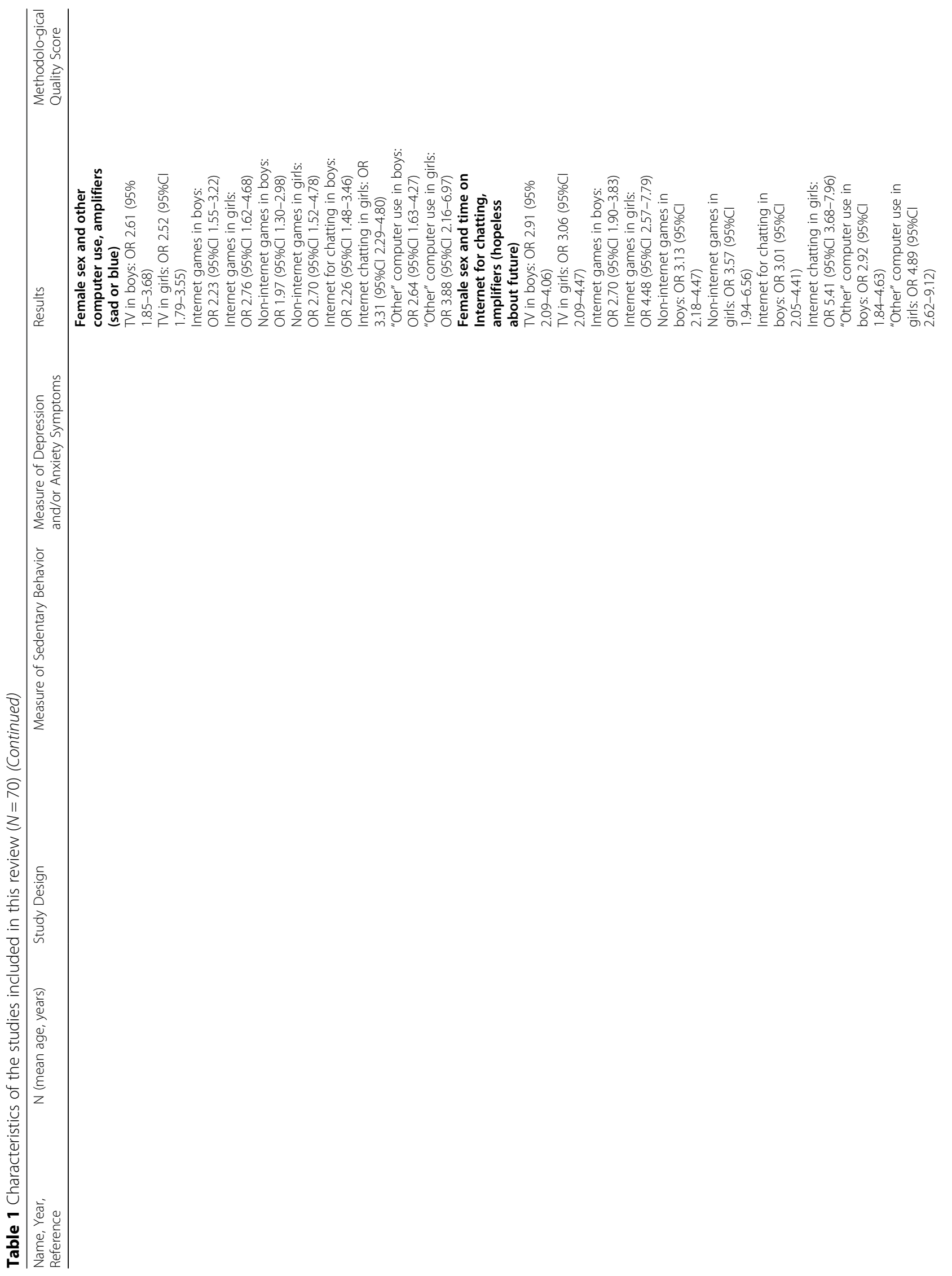




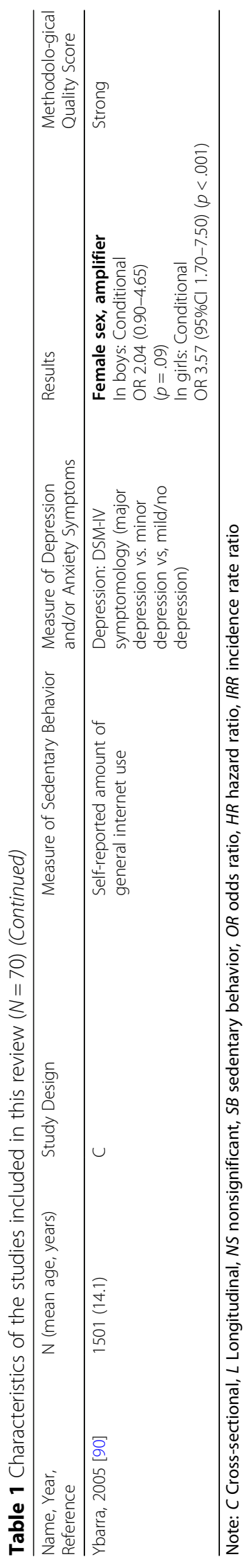


found female sex as an amplifier of screen-based SBanxiety symptom associations [29, 43, 69, 70, 87]; while one study found that sedentary boys had more symptoms of anxiety compared to sedentary girls [67]. The summary result for moderation of screen-based SB-anxiety symptom associations by sex is null (30.0\% of studies).

\section{Age (depressive symptoms: $n=6$; anxiety symptoms: $n=$ 1)}

A cross-sectional study in 8029 students aged 10 to16 years old found that compared to the younger children in the sample, adolescents who met screen-time recommendations were less likely to develop depressive symptoms [60]. However, a longitudinal study of over 1700 adolescents found that screen-based SB was unrelated to symptoms of depression in those in early- and late- adolescence, however significant positive associations emerged in those in mid-adolescence [50]. Four studies (one among a clinical sample) with smaller sample sizes found that age was not a significant moderator of screen-based SB-depressive symptom associations [61, $72,74,76]$. Thus, there is inconsistent evidence (33.3\% of studies) for age as a moderator of screen-based SBdepressive symptom associations.

Only one investigation assessed age as a moderator of screen-based SB-anxiety symptom associations; this longitudinal and bi-directional study of over 500 young children did not provide evidence for age as a moderator (null interaction term) [72]. Because fewer than four studies assessed age as a moderator of screen-based SBanxiety symptom associations, there is inconsistent evidence for moderation by age.

\section{Variables relating to country of origin/cultural factors (depressive symptoms: $n=2$; anxiety symptoms: $n=0$ )} McHale et al. found that an aspect of Mexican cultural orientation, parental educational value, modified the relationship between TV viewing and depressive symptoms; symptoms of depression and TV viewing were only related to one another among children with fathers with low educational value in this cross-sectional study of 469 youth [65]. Additionally, a study conducted among Japanese and Czech children concluded that videogame playing reduced symptoms of depression in the Japanese children, while there were no associations found in the Czech sample [59]. Given the few available studies, there is inconsistent evidence for moderation by cultural factors.

\section{Physical activity (depressive symptoms: $n=6$; anxiety symptoms: $n=3$ )}

Three cross-sectional studies among adolescents found that moderate-to-vigorous PA or vigorous PA buffered screenbased SB-depressive symptom associations [30, 51, 55].
Contrarily, three studies among children and adolescents did not provide evidence for PA, including in the form of physical education classes and organized sports, as a significant moderator $[26,60,83]$. Taken together, there is inconsistent evidence (50.0\% of studies) for PA as a moderator of screen-based SB-depressive symptom associations; however, among the studies with significant findings, $100.0 \%$ identified PA as a buffer of associations.

Only three studies assessed PA as a moderator of the relationship between screen-based SB and symptoms of anxiety. Two found that vigorous PA weakened screenbased SB-anxiety symptom associations [30, 51], while one did not provide evidence for leisure-time PA moderating screen-based SB-anxiety symptom associations [26]. Given the limited number of studies, there is inconsistent evidence for PA as a moderator of screen-based SB-anxiety symptom associations.

Other potential moderators (depressive symptoms: $n=11$; anxiety symptoms: $n=8$ )

Twelve studies investigated potential moderators that do not fall into the above categories. Three studies assessed how different peer/social factors (e.g., perceived friendship quality, in-person social interactions) may influence the strength of the relationship between screen-based SB and internalizing symptoms. For example, a recent longitudinal investigation revealed a three-way interaction between screen-based SB, sex, and social context in adolescents; girls who played videogames with peers were more likely to experience symptoms of anxiety, while boys who played videogames with peers were less likely to experience symptoms of anxiety [70]. In another study, there were no screen-based SB-internalizing symptom associations among youth with medium to high perceived friendship quality; while among children with low perceived friendship quality, instant messaging predicted fewer depressive symptoms and surfing the web was related to more depressive and anxiety symptoms in this subgroup [80]. The same study did not identify a threeway interaction between screen-based SB, sex, and perceived friendship quality among the sample [80]. Lastly, in a study of a nationally-representative sample, Twenge et al. found that social media use was only related to depressive outcomes among those with low in-person social interactions [84]. With the limited number of studies across different conceptualizations of the peer and social environment, there is inconsistent evidence for peer/social factors as moderators of screen-based SB-internalizing symptom associations.

Three studies investigated parental factors as potential moderators. Parental communication and parental involvement were not significant moderators of screenbased SB-internalizing symptom associations in studies among children and adolescents $[49,66]$. Lastly, parental 
alcoholism did not moderate screen-based SB-depressive symptom associations, while it was an amplifier of the associations between surfing the web, playing videogames, and anxiety symptoms among a sample of 328 adolescents [69]. There is inconsistent evidence for parental factors moderating screen-based SB-internalizing symptom associations due to the limited number of available studies.

Four studies assessed potential moderation by a number of indicators and proxies for socioeconomic status including parental education, household income, and neighborhood-level socioeconomic characteristics, with each study providing no evidence of moderation [23, 34, 66, 72]. Taken together the summary result is null $(0.0 \%$ of studies $)$ for socioeconomic status as a moderator of screen-based SBinternalizing symptom associations.

Four studies looked at additional variables as potential moderators that do not fall into the above subcategories. Kim and Ahn found that neighborhood divorce rate weakened the positive longitudinal relationship between screen-based SB and depressive symptoms, whereas population size and education were not moderators [57]. In one longitudinal study of over 7000 pre-adolescent youth, investigators found that self-rated general health and pubertal status do not moderate screen-based SBinternalizing symptom associations [23]. Kleppang et al. assessed if the year of investigation (2001 vs. 2009) influenced the strength of screen-based SB-internalizing symptom associations and found no evidence of moderation [58]. Lastly, Internet use and sleep duration were independently associated with depressive symptoms, however the interaction between these two variables was not significant, and thus the strength of the association between Internet use and depressive symptoms did not vary by sleep duration [37].

\section{Type of screen-based sedentary behavior}

Screen-based SB was conceptualized differently across studies, which may have influenced the strength of the observed associations with internalizing symptoms. Screen-based SB was typically defined as TV viewing, computer use, and videogame playing; resulting in investigators stratifying analyses by screen-type. Twenty-four studies provided evidence for differential associations by screen-type (e.g., TV viewing vs. computer use) when looking at screen-based SB in relation to depressive or anxiety symptoms; while eleven studies indicated that type of screen-based SB did not influence the strength of the observed associations. Taken together, there is significant evidence $(68.6 \%$ of studies) of moderation by screen-type. Below, these individual studies are reviewed in more detail by screen-type.

\section{Comparison of associations of TV viewing with} internalizing symptoms vs. another screen-based SB (depressive symptoms: $n=29$; anxiety symptoms: $n=13$ ) More than half of the studies $(n=16$, two among clinical samples) found that TV viewing was more weakly related to depressive symptoms compared to at least one other form of screen-based SB, such as computer use and videogame playing $[35,40-42,50,54,61-64,67,68$, $76,84,86,87]$. Three (one among a clinical sample) studies determined that TV viewing was related to depressive symptoms, with similar effect estimates compared to other electronic use investigated [35, 42, 77]. Five studies indicated that TV viewing was more strongly related to depressive symptoms compared to at least one other form of screen-based SB [28, 31, 33, 44, 73 ] and seven studies (one among a clinical sample) provided evidence that all forms of screen-based SB (including TV) were unrelated to depressive symptoms $[24,28$, $47,69,71,72,74]$. Lastly, Yang et al. found that TV viewing among girls was more strongly related to the depressive symptom of feeling sad or having little interest in doing things compared to other screen-types [89]; however, this study has also demonstrated that TV viewing was more weakly related to other symptoms of depression such as crying easily or feeling hopeless about the future, compared to other forms of screen-based SB [89].

Thirteen studies (two among clinical samples) examined TV viewing-anxiety symptom associations among youth. A majority $(n=9)$ of studies found that compared to at least one other type of screen-based SB, TV viewing was not as strongly related to symptoms of anxiety $[42,62-64$, 67, 69, 86-88]. One study indicated that TV viewing, along with other forms of screen-based SB, were each related to symptoms of anxiety with similar magnitudes (cross-sectionally only) [42]. Lastly, four investigations found that all forms of screen-based SB (including TV) were unrelated to anxiety symptoms $[24,47,71,72]$.

\section{Comparison of associations of computer use/internet use with internalizing symptoms vs. another screen-based SB (depressive symptoms: $n=29$; anxiety symptoms: $n=12$ )} Of the 29 studies that assessed the relationship between computer use and depressive symptoms, five determined that computer use was more weakly associated with depressive symptoms compared to at least one other form of screen-based SB [35, 44, 50, 67, 84]; and two studies found a protective association between computer use and depressive symptoms while simultaneously demonstrating either null or positive associations between another form of screen-based SB and depressive symptoms $[33,64]$. Thirteen studies (two among clinical samples) concluded that computer usage was more strongly related to depressive symptoms compared at least one 
other form of screen-based SB [31, 40-42, 54, 61-63, 68, $76,86,87,89]$. Cross-sectionally, Bickham et al. did not find associations between any form screen-based SB and depressive symptoms, however longitudinally, TV viewing and mobile phone use were positively associated with depressive symptoms while computer and videogame use remained unrelated to depressive symptoms [28]. Three studies (one among a clinical sample) concluded that computer use was associated with depressive symptoms, with similar effect estimates compared to the other forms of screen-based SB investigated [35, 42, 77]. Finally, seven studies (one among a clinical sample) found that engagement in each screen-type (including computer use) was unrelated to depressive symptoms $[24,69,71,72,74,85,92]$.

Four studies (two among clinical samples) found that computer use was positively associated with symptoms of anxiety, and that computer use was more strongly related to symptoms of anxiety than other forms of screen-based SB [62, 69, 86, 87]; whereas one study found that computer use was protective against symptoms of anxiety [64]. Only two studies found that computer use was more weakly associated with symptoms of anxiety compared to at least one other form of screenbased SB [63, 67]. Cross-sectionally, Gopinath et al. found that each type of screen-based SB (including computer use) was similarly related to symptoms of anxiety, whereas longitudinally, computer use was more strongly related to symptoms of anxiety compared to TV viewing [42]. Lastly, four studies found that each form of screenbased SB assessed was unrelated to symptoms of anxiety $[24,71,72,92]$.

\section{Comparisons of associations of videogame playing with internalizing symptoms vs. another screen-based SB (depressive symptoms: $n=21$; anxiety symptoms: $n=12$ )} Eleven of 21 studies (two among clinical samples) concluded that videogames were more strongly related to depressive symptoms compared to at least one other form of screen-based SB [41, 42, 61-64, 67, 68, 76, 86, 87]; while four studies found that videogame playing was more weakly related to symptoms of depression compared to at least one other screen-type [28, 35, 50, 73]. Further, one study found that videogames were protective against symptoms of depression [31]. Videogame playing, along with other forms of screen-based SB were each similarly positively associated with depressive symptoms in two studies [35, 42]. Lastly, six studies (one among a clinical sample) found that videogame playing (along with all other screen-types) was not related to depressive symptoms [24, 28, 69, 71, 72, 74].

Seven of twelve studies (two among clinical samples) found a stronger association between videogame playing and symptoms of anxiety as compared to another form of screen-based SB [42, 62-64, 67, 86, 87]. Alternatively, one study indicated that videogames were more weakly associated with anxiety symptoms as compared to other screen-types [88]. Ohannessian found a positive association between videogames and symptoms of anxiety in girls, but a negative association between these two variables in boys [69]. Lastly, one found that engagement in all screen-types were similarly positively associated with anxiety symptoms [42], while three studies found that each screen-based SB was similarly unrelated to anxiety symptoms $[24,71,72]$.

\section{Comparisons of associations of other screen-based sedentary behaviors with internalizing symptoms (depressive symptoms: $n=10$; anxiety symptoms: $n=4$ )}

In addition to the three main types of screen-based SB (TV viewing, computer use, and videogame playing), there were some investigations of other screen-types in relation to internalizing symptoms. Six studies assessed how texting/mobile phone use related to depressive symptoms; and of these, only one study found that texting/mobile phone use was more strongly related to depressive symptoms compared to other screen-types longitudinally [28]. Alternatively, two studies found that texting/mobile phone use had weaker associations with depressive symptoms compared to other forms of screen-based SB [61, 64]; while three studies concluded that texting/mobile phones were similarly unrelated to depressive symptoms compared to other forms of screen-based SB [69, 72, 85]. Social media was also a screen-based SB that was investigated in two studies; both demonstrated that social media use was more strongly related to depressive symptoms compared to other forms of screen-based SB [50, 84]. In another study, tablet use on weekdays was more strongly related to depressive symptoms compared to other screen-types, however this pattern did not emerge on weekend days, when all screen-based SB were similarly positively associated with depressive symptoms [35]. Lastly, Primack et al. found that watching videos was unrelated to depressive symptoms, compared to TV viewing which was positively associated with depressive symptoms in a longitudinal study of over 4000 participants [73].

Only four studies investigated the relationship between other types of screen-based SB and symptoms of anxiety. Specifically, two studies found that texting was more weakly related to symptoms of anxiety as compared to at least one other form of screen-based SB [64, 69]. On the other hand, one study found that mobile phone use was similarly bi-directionally unrelated to symptoms of anxiety compared to other screen-types [72]. Lastly, studying on electronic devices and going on social networking sites on schooldays, specifically, were more strongly related to symptoms of anxiety compared to other forms 
of screen-based SB, such as watching videos, in a study of over 2600 adolescents [88]. On non-school days, however, only social networking sites were related to symptoms of anxiety in this sample [88].

\section{Sensitivity analyses among studies of high methodological quality (depressive symptoms: $n=6$; anxiety symptoms: $n=1$ )}

Sensitivity analyses of the six studies with high methodological quality were conducted to gain a better understanding of findings across studies that were rated as the least likely to be subject to biases; five were of depressive symptoms $[33,53,57,73,90]$ and one was of depressive and anxiety symptoms [30].

Sex was tested as a moderator in three studies, with mixed findings $[53,73,90]$. Stratified analyses among approximately 1500 adolescents indicated that Internet use was related to depressive symptoms among girls, but not boys [90]. However, a later longitudinal study of over 4000 adolescents found that female sex was a buffer of screen-based SB-depressive symptom associations via a statistical test of interaction [73]. Lastly, a study of the association between clusters of energy balance behaviors and depressive symptoms found that those within the clusters encompassing the highest levels of screen-based SB had the greatest level of depressive symptoms, regardless of sex [53].

The influence of screen-type on screen-based SBdepressive symptom associations was investigated in two studies, and differences by screen-type emerged in both $[33,73]$. In a longitudinal study of over 10,000 adolescents, investigators found that Internet games were protective of subsequent depressive symptoms, while TV viewing was unrelated to depressive symptoms [33]. On the other hand, Primack et al. found that among the screen-types investigated (TV viewing, videos, and videogame playing), only TV viewing was longitudinally related to increased odds of depressive symptoms [73].

In a longitudinal study of middle-schoolers, Kim et al. found that among various neighborhood characteristics, including divorce rate, population size, and education level, only neighborhood divorce rate influenced the strength of the association between videogame playing and subsequent depressive symptoms [57]. Neighborhoods with a higher neighborhood divorce rate buffered the association between videogame playing and depressive symptoms, as indicated by a significant test for interaction [57]. Lastly, a study of over 5000 adolescents demonstrated that vigorous PA buffers the association between screen-based SB, depressive symptoms, and anxiety symptoms [30].

\section{Discussion}

The aim of this paper was to summarize the evidence for potential moderators of screen-based $\mathrm{SB}$ and internalizing symptom associations to better understand the heterogeneity of previous study findings, identify atrisk populations, and to pose future research directions for the field. Screen-type most consistently influenced the strength of the association between screen-based SB and internalizing symptoms. However, the evidence for symptoms of anxiety, specifically, is more limited, and therefore findings should be interpreted with caution. Currently, the literature provides inconsistent evidence for moderating effects by sex, age, cultural characteristics, PA, peer factors (e.g., friendship quality and social context), and parental factors (e.g., parental communication). Further, there is no evidence of moderation by socioeconomic status.

\section{Synthesis of findings and implications}

Our results indicate that screen-type influences the strength of the screen-based SB-depressive symptoms relationship; TV viewing appears less likely to be associated with depressive symptoms, compared to computer use and videogame playing. Screen-specific associations highlight that psychosocial mechanisms, which only occur when one is engaged in certain forms of screenbased SB, are likely to explain the link between screen time and internalizing symptoms. For example, being a victim of cyber-bullying may contribute to the positive association between computer/Internet use, specifically, and depressive symptoms [93, 94]. Further, the online environment may be especially hostile for adolescent girls, who report being exposed to more unintentional negative online content (sexual content, slander) compared to boys [95]. Additionally, passive social media use, the monitoring of others' lives by viewing the content of their profiles, may increase susceptibility to internalizing symptoms [96, 97]; passive social media use may be particularly detrimental because it increases one's feelings of inferiority via upward social comparison and can increase perceived loneliness [98]. On the other hand, utilizing the computer for instrumental reasons, such for school work or email, is not associated with increased symptoms of depression in youth [82]. Taken together, computer/Internet use may be more worse for the emotional well-being of youth compared to other forms of screen-based SB when it is utilized for specific purposes.

Similarly, only certain forms of videogaming may have negative consequences for youth. A study among children found that violent videogames were correlated with depressive symptoms, while videogames without violent content were unrelated to depressive outcomes [99]. Frequent and competitive video gaming (playing against others) may also pose negative implications for psychosocial well-being [100]. Conversely, other work has shown that videogaming may have a positive influence 
on development [101]. Playing casual videogames-ones that are fun, easy to learn, and readily accessible (i.e. $B e-$ jeweled II) - can improve mood and promote relaxation [102, 103]; further, a review and meta-analysis provides evidence for the efficacy of reducing internalizing symptoms with certain types of videogames, even among clinical samples [104]. Thus, emotional influence of videogames may depend on the content, type, and purpose of the videogame play. Taken together with our findings that computer and videogame use are more likely to be associated with depressive symptoms compared to television viewing, interventions aimed at reducing symptoms of depression via reducing sedentary time may most effective if they targeted computer use and videogame playing, specifically. However, future research should attempt to gain a better understanding of how specific behaviors within computer and videogame use (e.g., passive vs. active social media use) relate to internalizing symptoms prior to the development of intervention strategies, given that not all types and content of computer use and videogame play may have emotional consequences.

Sex was among the most commonly-studied moderators of screen-based SB-internalizing symptom associations; our review revealed inconsistent evidence for moderation by sex. Inconsistencies in the evidence for sex as a moderator may be due unexplored three-way interactions between sex, screen-based SB (or internalizing symptoms), and another third variable, for example age. It is conceivable that sex may be an important moderator of screen-based SB-internalizing symptom associations only during more vulnerable periods in development when sex differences in activity and internalizing symptom levels become more apparent [105108], and not during earlier or later stages in development. However, more investigations of the potential three-way interaction between sex, screen-based SB (or internalizing symptoms), and age are needed.

Across studies that did find significant moderation by sex, it appears that sedentary girls, but not boys, may be more susceptible to depressive symptoms. Girls have higher rates of depression which may, in part, be a result of biological and cognitive factors such as hormonal changes [109] and ruminative coping [110]. On a behavioral level, girls may prefer more unhealthy forms of screen-based SB compared to boys; a recent study found that girls were significantly more likely than boys to use social networking sites for more than two hours daily [111]. The use of social networking sites may be particularly deleterious because they can increase one's susceptibility to depressive symptoms via upward social comparison [112]. On a psychosocial level, boys and girls tend to engage in screen-based SB in similar social contexts; youth oftentimes engage in screen-based SB with others, including with friends and family members [113, 114]. However, the social context of screen-based SB may interact with sex such that screen-based SB with friends may be protective against internalizing symptoms among boys, but not girls [70]. Although sedentary girls appear to be at greater risk compared to sedentary boys, a more nuanced understanding mechanisms underlying the interaction between sex and screen-based SB on internalizing symptoms is still needed prior to the development of intervention strategies. Future research should investigate potential sex differences in (1) preferred forms of screen-based SB, (2) psychosocial behaviors (e.g., social comparison) while engaging in screenbased SB, and (3) social context of screen-based SB, to further our understanding sedentary girls' potential vulnerabilities. Once this is accomplished, future interventions aimed at decoupling screen-based SB and internalizing symptoms may be tailored towards specific screen-based SB among at-risk groups, increasing the likelihood of intervention success.

The few studies investigating PA, including organized sports, as a moderator suggest that it may weaken screen-based SB-internalizing symptom associations. Participation in sports is associated with fewer symptoms of depression and anxiety in some children [115], which may be explained by increases in self-esteem and social support [116]. However, participation in organized sports may not be an appropriate intervention strategy for all youth; students identifying as lesbian, gay, bisexual, transgender, and queer are commonly bullied in the school-based athletic setting (physical education class and afterschool sports) [117]. Structured aerobic PA interventions, consisting of activities such as cycling and jogging, have also demonstrated efficacy for reducing symptoms of depression and anxiety, even among clinical populations $[118,119]$. However, a notable limitation of structured PA interventions is their lack of sustainability in the real-world setting. Adherence to PA programs steadily decreases over time, especially among those with depressive symptoms [120]. Therefore, future investigations should test additional, less-understood, more feasible, and enjoyable forms PA as a moderator; as certain types of PA may be vital intervention strategies for decoupling screen-based SB and their associated emotional health consequences in the real-world setting.

\section{Suggestions for future research}

While continuing to test variables such as sex, types of $\mathrm{PA}$, and content with each type of screen-based SB as potential moderators is pertinent to future research, it should be recognized that the current body of literature contains limitations that must be addressed with future, high quality investigations. First, more than half of the 
studies in this review were cross-sectional $(n=46)$, which prevents our ability to draw causal conclusions and limits our understanding of the directionality of associations. Future research should focus on gaining a better understanding of the directionality of screenbased SB-internalizing symptom associations as recent studies indicate that screen-based SB and internalizing symptoms may have a bi-directional relationship [121, 122]. However, additional studies with longitudinal and experimental designs are needed to assist with determining the potential for causal and bi-directional associations between screen-based SB and internalizing symptoms. Future studies aimed at pinpointing the directionality of associations will ultimately strengthen our ability to identify critical intervention points for decoupling screen-based SB and internalizing symptoms.

Second, a majority of the studies in the present review relied on paper-and-pencil, retrospective self-reports of engagement in screen-based SB. A combination of device-based measures (e.g., inclinometers, accelerometers) and real-time self-reports (e.g., ecological momentary assessment) should be used to limit recall bias and provide more detailed information on types and contexts of screen-based SB, as this review suggests these factors can influence associations with internalizing symptoms among youth [123].

Third, the body of evidence for depressive symptoms is much larger than that for anxiety symptoms. Anxiety symptoms are likely related to screen-based SB, but the moderating factors of this association remain unclear, due to the limited evidence available. One potential mechanism for this trend is that the physiologic hyperarousal associated with anxiety symptoms may reduce the likelihood of being influenced by moderators as compared to depressive symptoms, where hyperarousal is not present [124]. Similarly, many studies used measures that combined depressive and anxiety symptoms within the same subscale; making it difficult to interpret if results are applicable to depressive symptoms only, anxiety symptoms only, or both. Recent evidence indicates that differential associations appear between screen-based SB and symptoms of various forms of anxiety; specifically, screen-based SB may be related to symptoms of generalized anxiety and social phobia, but not panic disorder [125]. Therefore, future research should be directed toward gaining a better understanding of anxiety symptoms and screen-based SB in addition to depressive symptoms, by using separate scales to quantify symptoms of each internalizing disorder.

Lastly, a majority of the evidence for sex as a moderator is based on stratified analyses without statistical tests for interaction, therefore results must be interpreted with caution. Future research should rely only on formal statistical tests for interaction when assessing moderation. Timely interventions for decoupling screenbased SB and depressive and anxiety symptoms are critically needed, as the prevalence of certain (and potentially more deleterious) forms screen-based SB continues to rise [126, 127]; the abovementioned suggestions for future research may be pivotal in designing and optimizing future intervention strategies.

\section{Strengths and limitations}

A strength of the present review is the systematic search strategy used, which yielded a considerable number of studies included in the present review; however, there is the possibility that our search strategy may have missed relevant studies on the topic. Another limitation of this review is that only published articles written in English were included, index terms were not used, and a "grey literature" search was not included; therefore, our evidence may be biased towards positive results due to publication bias. Furthermore, studies that included screen-based SB in addition to non-screen-based SB (e.g., reading, homework) as a composite variable were excluded. Similarly, studies examining the nuances within the screen-based SB construct, such as content, weren't systematically reviewed in the present article.

\section{Conclusions}

This review summarizes moderators of the screen-based SB-internalizing symptom associations, discusses potential mechanistic explanations, and poses directions for future research. There is consistent evidence that screen-type influences the strength of the association between screen-based SB and internalizing symptoms. Less consistent evidence is available for female sex as an amplifier and physical activity as a buffer, therefore more research is needed on these factors to identify the possibility of vulnerable populations and tailored intervention strategies. Additionally, more evidence is needed for anxiety symptoms in particular. Gaining a thorough understanding of these complex relationships will lead to effective intervention strategies for improving the emotional and physical health of youth to ultimately prevent morbidity and mortality later in life.

\section{Abbreviations \\ SB: Sedentary behavior; PA: Physical activity}

\section{Acknowledgments}

None.

Authors' contributions

JZ, BRB, and AML substantially contributed to the study design. JZ and KI conducted the systematic review and collected relevant article information.

JZ drafted the manuscript; KI, BRB, and AML critically reviewed the manuscript's content. All authors have read and consented to the manuscript. The author(s) read and approved the final manuscript. 


\section{Funding}

This project was partially funded by the National Institutes of Health Cancer Control and Epidemiology Research Training Grant (T32 CA009492) and the University of Southern California Graduate Student Provost Fellowship.

\section{Availability of data and materials \\ Not applicable.}

\section{Ethics approval and consent to participate}

Not applicable.

\section{Consent for publication}

Not applicable.

\section{Competing interests}

The authors declare that they have no competing interests.

\section{Author details}

${ }^{1}$ Department of Preventive Medicine, Keck School of Medicine of University of Southern California, 2001 North Soto Street, Third Floor, California, Los Angeles 90032, USA. ²Department of Psychology, University of Southern California, Los Angeles, USA.

\section{Received: 5 March 2019 Accepted: 24 March 2020}

\section{Published online: 10 April 2020}

\section{References}

1. Pate RR, Mitchell JA, Byun W, Dowda M. Sedentary behaviour in youth. Br J Sports Med. 2011:45(11):906-13.

2. Thomas G, Bennie JA, De Cocker K, Castro O, Biddle SJ. A descriptive epidemiology of screen-based devices by children and adolescents: a scoping review of 130 surveillance studies since. Child Indic Res. 2000;2019: $1-16$.

3. Gordon-Larsen P, Nelson MC, Popkin BM. Longitudinal physical activity and sedentary behavior trends: adolescence to adulthood. Am J Prev Med. 2004; 27(4):277-83.

4. McVeigh J, Smith A, Howie E, Straker L. Trajectories of television watching from childhood to early adulthood and their association with body composition and mental health outcomes in young adults. PLoS One. 2016; 11(4):e0152879.

5. Dahl RE. Adolescent brain development: a period of vulnerabilities and opportunities. Keynote address. Ann N Y Acad Sci. 2004;1021(1):1-22.

6. Merikangas KR, He J-p, Burstein M, Swanson SA, Avenevoli S, Cui L, et al. Lifetime prevalence of mental disorders in US adolescents: results from the National Comorbidity Survey Replication-Adolescent Supplement (NCS-A). J Am Acad Child Adolesc Psychiatry. 2010;49(10):980-9.

7. Saluja G, lachan R, Scheidt PC, Overpeck MD, Sun W, Giedd JN. Prevalence of and risk factors for depressive symptoms among young adolescents. Arch Pediatr Adolesc Med. 2004;158(8):760-5.

8. Beesdo K, Knappe S, Pine DS. Anxiety and anxiety disorders in children and adolescents: developmental issues and implications for DSM-V. Psychiatr Clin N Am. 2009;32(3):483-524.

9. Thapar A, Collishaw S, Pine DS, Thapar AK. Depression in adolescence. Lancet. 2012;379(9820):1056-67.

10. Wolitzky-Taylor K, Bobova L, Zinbarg RE, Mineka S, Craske MG. Longitudinal investigation of the impact of anxiety and mood disorders in adolescence on subsequent substance use disorder onset and vice versa. Addict Behav. 2012;37(8):982-5

11. Jaycox LH, Stein BD, Paddock S, Miles JN, Chandra A, Meredith LS, et al. Impact of teen depression on academic, social, and physical functioning Pediatrics. 2009;124(4):e596-605.

12. Zhai $L$, Zhang $Y$, Zhang D. Sedentary behaviour and the risk of depression: a meta-analysis. Br J Sports Med. 2015;49(11):705-9.

13. Hoare $\mathrm{E}$, Milton $\mathrm{K}$, Foster $\mathrm{C}$, Allender $\mathrm{S}$. The associations between sedentary behaviour and mental health among adolescents: a systematic review. Int J Behav Nutr Phys Act. 2016:13(1):108

14. Liu M, Wu L, Yao S. Dose-response association of screen time-based sedentary behaviour in children and adolescents and depression: a metaanalysis of observational studies. Br J Sports Med. 2016;50(20):1252-8.

15. Rubin KH, Burgess KB. Social withdrawal and anxiety. Dev Psychopathol Anxiety. 2001:407-34.
16. Suchert V, Hanewinkel R, Isensee B. Sedentary behavior, depressed affect, and indicators of mental well-being in adolescence: does the screen only matter for girls? J Adolesc. 2015;42:50-8.

17. Davison KK, Werder JL, Trost SG, Baker BL, Birch LL. Why are early maturing girls less active? Links between pubertal development, psychological wellbeing, and physical activity among girls at ages 11 and 13. Soc Sci Med (1982). 2007;64(12):2391-2404.

18. Moher D, Liberati A, Tetzlaff J, Altman DG. Preferred reporting items for systematic reviews and meta-analyses: the PRISMA statement. Ann Intern Med. 2009;151(4):264-9.

19. Rodriguez-Ayllon M, Cadenas-Sanchez C, Estevez-Lopez F, Muñoz NE, MoraGonzalez J, Migueles JH, et al. Role of physical activity and sedentary behavior in the mental health of preschoolers, children and adolescents: a systematic review and meta-analysis. Sports Med. 2019:1-28.

20. Smith JJ, Eather N, Morgan PJ, Plotnikoff RC, Faigenbaum AD, Lubans DR. The health benefits of muscular fitness for children and adolescents: a systematic review and meta-analysis. Sports medicine (Auckland, NZ). 2014; 44(9):1209-1223.

21. Thomas H. Quality assessment tool for quantitative studies. Toronto: Effective Public Health Practice Project McMaster University; 2003.

22. Teychenne M, Costigan SA, Parker K. The association between sedentary behaviour and risk of anxiety: a systematic review. BMC Public Health. 2015; 15:513.

23. Allen MS, Vella SA. Screen-based sedentary behaviour and psychosocial well-being in childhood: cross-sectional and longitudinal associations. Ment Health Phys Act. 2015:9:41-7.

24. Baer S, Saran K, Green DA. Computer/gaming station use in youth: correlations among use, addiction and functional impairment. Paediatr Child Health (Canada). 2012;17(8):427-31.

25. Barcaccia B, Balestrini V, Saliani AM, Baiocco R, Mancini F, Schneider BH. Dysfunctional eating behaviors, anxiety, and depression in Italian boys and girls: the role of mass media. Rev Bras Psiquiatr. (Sao Paulo, Brazil : 1999). 2018;40(1):72-77.

26. Bélair M-A, Kohen DE, Kingsbury M, Colman I. Relationship between leisure time physical activity, sedentary behaviour and symptoms of depression and anxiety: evidence from a population-based sample of Canadian adolescents. BMJ Open. 2018;8(10):e021119.

27. Belanger RE, Akre C, Berchtold A, Michaud PA. A U-shaped association between intensity of internet use and adolescent health. Pediatrics. 2011; 127(2):e330-5.

28. Bickham DS, Hswen Y, Rich M. Media use and depression: exposure, household rules, and symptoms among young adolescents in the USA. Int Public Health. 2015:60(2):147-55.

29. Brodersen NH, Steptoe A, Williamson S, Wardle J. Sociodemographic, developmental, environmental, and psychological correlates of physical activity and sedentary behavior at age 11 to 12. Ann Behav Med. 2005;29(1): 2-11

30. Cao H, Qian Q, Weng T, Yuan C, Sun Y, Wang H, et al. Screen time, physical activity and mental health among urban adolescents in China. Prev Med. 2011;53(4-5):316-20

31. Casiano H, Kinley DJ, Katz LY, Chartier MJ, Sareen J. Media use and health outcomes in adolescents: findings from a nationally representative survey. J Can Acad Child Adolesc Psychiatry. 2012;21(4):296-301.

32. Castillo F, Francis L, Wylie-Rosett J, Isasi CR. Depressive symptoms are associated with excess weight and unhealthier lifestyle behaviors in urban adolescents. Child Obes. 2014;10(5):400-7.

33. Chen SY, Lu L. After-school time use in Taiwan: effects on educational achievement and well-being. Adolescence. 2009;44(176):891-909.

34. Cho D, Park CL. Smoking and sedentary behavior changes from adolescence to emerging adulthood: a multilevel modeling perspective. Prev Med. 2017;101:223-8.

35. Dennison-Farris M, Sisson SB, Stephens L, Morris AS, Dickens R. Obesogenic Behaviors, Self-Efficacy, and Depressive Symptoms in American Indian Children. American Indian \& Alaska Native Mental Health Research. J Natl Center. 2017;24(2):18-39.

36. Desai RA, Krishnan-Sarin S, Cavallo D, Potenza MN. Video-gaming among high school students: health correlates, gender differences, and problematic gaming. Pediatrics. 2010;126(6):e1414-24.

37. Do YK, Shin E, Bautista MA, Foo K. The associations between self-reported sleep duration and adolescent health outcomes: what is the role of time spent on internet use? Sleep Med. 2013;14(2):195-200. 
38. Durkin K, Barber B. Not so doomed: computer game play and positive adolescent development. J Appl Dev Psychol. 2002;23(4):373-92.

39. Fulkerson JA, Sherwood NE, Perry CL, Neumark-Sztainer D, Story M. Depressive symptoms and adolescent eating and health behaviors: a multifaceted view in a population-based sample. Prev Med. 2004;38(6):86575.

40. Godinho J, Araujo J, Barros H, Ramos E. Characteristics associated with media use in early adolescence. Cad Saude Publica. 2014;30(3):587-98.

41. Goldfield GS, Murray M, Maras D, Wilson AL, Phillips P, Kenny GP, et al. Screen time is associated with depressive symptomatology among obese adolescents: a HEARTY study. Eur J Pediatr. 2016;175(7):909-19.

42. Gopinath B, Hardy LL, Baur LA, Burlutsky G, Mitchell P. Physical activity and sedentary behaviors and health-related quality of life in adolescents. Pediatrics. 2012;130(1):e167-74.

43. Griffiths LJ, Dowda M, Dezateux C, Pate R. Associations between sport and screen-entertainment with mental health problems in 5-year-old children. Int J Behav Nutr Phys Act. 2010;7:30.

44. Grontved A, Singhammer J, Froberg K, Moller NC, Pan A, Pfeiffer KA, et al. A prospective study of screen time in adolescence and depression symptoms in young adulthood. Prev Med. 2015;81:108-13.

45. Hamer M, Yates T, Sherar LB, Clemes SA, Shankar A. Association of after school sedentary behaviour in adolescence with mental wellbeing in adulthood. Prev Med. 2016;87:6-10.

46. Hayward J, Jacka FN, Skouteris H, Millar L, Strugnell C, Swinburn BA, et al. Lifestyle factors and adolescent depressive symptomatology: associations and effect sizes of diet, physical activity and sedentary behaviour. Aust N Z J Psychiatry. 2016.

47. Hinkley T, Verbestel V, Ahrens W, Lissner L, Molnar D, Moreno LA, et al. Early childhood electronic media use as a predictor of poorer well-being: a prospective cohort study. JAMA Pediatr. 2014;168(5):485-92.

48. Hoare E, Millar L, Fuller-Tyszkiewicz M, Skouteris H, Nichols M, Jacka F, et al. Associations between obesogenic risk and depressive symptomatology in Australian adolescents: a cross-sectional study. J Epidemiol Community Health. 2014;68(8):767-72.

49. Holtz P, Appel M. Internet use and video gaming predict problem behavior in early adolescence. J Adolesc. 2011;34(1):49-58.

50. Houghton S, Lawrence D, Hunter SC, Rosenberg M, Zadow C, Wood L, et al. Reciprocal relationships between trajectories of depressive symptoms and screen media use during adolescence. J Youth Adolesc. 2018;47(11):245367.

51. Hrafnkelsdottir SM, Brychta RJ, Rognvaldsdottir V, Gestsdottir S, Chen KY, Johannsson $E$, et al. Less screen time and more frequent vigorous physical activity is associated with lower risk of reporting negative mental health symptoms among Icelandic adolescents. PloS one. 2018;13(4):e0196286. https://doi.org/10.1371/journal.pone.0196286.

52. Hume C, Timperio A, Veitch J, Salmon J, Crawford D, Ball K. Physical activity, sedentary behavior, and depressive symptoms among adolescents. J Phys Act Health. 2011:8(2):152-6.

53. lannotti RJ, Wang J. Patterns of physical activity, sedentary behavior, and diet in U.S. adolescents. J Adolesc Health. 2013;53(2):280-6.

54. Katon W, Richardson L, Russo J, McCarty CA, Rockhill C, McCauley E, et al. Depressive symptoms in adolescence: the association with multiple health risk behaviors. Gen Hosp Psychiatry. 2010;32(3):233-9.

55. Khan A, Burton NW. Is physical inactivity associated with depressive symptoms among adolescents with high screen time? Evidence from a developing country. Ment Health Phys Act. 2017;12:94-9.

56. Kim JY. The nonlinear association between internet using time for noneducational purposes and adolescent health. J Prev Med Public Health. 2012:45(1):37-46.

57. Kim HH, Ahn SJ. How does neighborhood quality moderate the association between online video game play and depression? A population-level analysis of Korean students. Cyberpsychol Behav Soc Netw. 2016;19(10):628-34

58. Kleppang AL, Thurston M, Hartz I, Hagquist C. Psychological distress among Norwegian adolescents: changes between 2001 and 2009 and associations with leisure time physical activity and screen-based sedentary behaviour. Scand J Public Health. 2019;47(2):166-73. https://doi.org/10.1177/ 1403494817716374

59. Krejci M, Wada K, Nakade M, Takeuchi H, Noji T, Harada T. Effects of video game playing on the circadian typology and mental health of young Czech and Japanese children. Psychology. 2011;2(07):674.
60. Kremer P, Elshaug C, Leslie E, Toumbourou JW, Patton GC, Williams J. Physical activity, leisure-time screen use and depression among children and young adolescents. J Sci Med Sport. 2014;17(2):183-7.

61. Lemola S, Perkinson-Gloor N, Brand S, Dewald-Kaufmann JF, Grob A Adolescents' electronic media use at night, sleep disturbance, and depressive symptoms in the smartphone age. J Youth Adolesc. 2014;44(2): 405-18.

62. Liu M, Ming Q, Yi J, Wang X, Yao S. Screen time on school days and risks for psychiatric symptoms and self-harm in mainland Chinese adolescents. Front Psychol. 2016;7:574.

63. Maras D, Flament MF, Murray M, Buchholz A, Henderson KA, Obeid N, et al. Screen time is associated with depression and anxiety in Canadian youth. Prev Med. 2015;73:133-8

64. Mathers M, Canterford L, Olds T, Hesketh K, Ridley K, Wake M. Electronic media use and adolescent health and well-being: cross-sectional community study. Acad Pediatr. 2009;9(5):307-14.

65. McHale SM, Updegraff KA, Kim JY, Cansler E. Cultural orientations, daily activities, and adjustment in Mexican American youth. J Youth Adolesc. 2009;38(5):627-41.

66. Mistry KB, Minkovitz CS, Strobino DM, Borzekowski DL. Children's television exposure and behavioral and social outcomes at 5.5 years: does timing of exposure matter? Pediatrics. 2007;120(4):762-9.

67. Mundy LK, Canterford L, Olds T, Allen NB, Patton GC. The association between electronic media and emotional and behavioral problems in late childhood. Acad Pediatr. 2017;17(6):620-4.

68. Nakamura H, Ohara K, Kouda K, Fujita Y, Mase T, Miyawaki C, et al. Combined influence of media use on subjective health in elementary school children in Japan: a population-based study. BMC Public Health. 2012;12:432

69. Ohannessian CM. Media use and adolescent psychological adjustment: an examination of gender differences. J Child Fam Stud. 2009;18(5):582-93.

70. Ohannessian CM. Video game play and anxiety during late adolescence: the moderating effects of gender and social context. J Affect Disord. 2018;226: 216-9.

71. Parkes A, Sweeting $H$, Wight D, Henderson M. Do television and electronic games predict children's psychosocial adjustment? Longitudinal research using the UK millennium cohort study. Arch Dis Child. 2013;98(5):341-8.

72. Poulain T, Vogel M, Neef M, Abicht F, Hilbert A, Genuneit J, et al. Reciprocal associations between electronic media use and behavioral difficulties in preschoolers. Int J Environ Res Public Health. 2018;15(4):814.

73. Primack BA, Swanier B, Georgiopoulos AM, Land SR, Fine MJ. Association between media use in adolescence and depression in young adulthood: a longitudinal study. Arch Gen Psychiatry. 2009;66(2):181-8.

74. Primack BA, Silk JS, DeLozier CR, Shadel WG, Dillman Carpentier FR, Dahl RE, et al. Using ecological momentary assessment to determine media use by individuals with and without major depressive disorder. Arch Pediatr Adolesc Med. 2011;165(4):360-5

75. Robinson M, Kendall GE, Jacoby P, Hands B, Beilin LJ, Silburn SR, et al. Lifestyle and demographic correlates of poor mental health in early adolescence. J Paediatr Child Health. 2011;47(1-2):54-61.

76. Romer D, Bagdasarov Z, More E. Older versus newer media and the wellbeing of United States youth: results from a national longitudinal panel. J Adolesc Health. 2013;52(5):613-9.

77. Rottenberg J, Yaroslavsky I, Carney RM, Freedland KE, George CJ, Baji I, et al. The association between major depressive disorder in childhood and risk factors for cardiovascular disease in adolescence. Psychosom Med. 2014; 76(2):122-7.

78. Schmitz KH, Lytle LA, Phillips GA, Murray DM, Birnbaum AS, Kubik MY. Psychosocial correlates of physical activity and sedentary leisure habits in young adolescents: the teens eating for energy and nutrition at school study. Prev Med. 2002;34(2):266-78.

79. Schreck M, Althoff R, Sibold J, Giummo C, Hudziak J, Bartels M, et al. Withdrawn behavior, leisure-time exercise behavior, and screen-time sedentary behavior in a clinical sample of youth. J Clin Sport Psychol. 2016; 10(3):206-21.

80. Selfhout MH, Branje SJ, Delsing M, ter Bogt TF, Meeus WH. Different types of internet use, depression, and social anxiety: the role of perceived friendship quality. J Adolesc. 2009:32(4):819-33.

81. Singer Ml, Slovak K, Frierson T, York P. Viewing preferences, symptoms of psychological trauma, and violent behaviors among children who watch television. J Am Acad Child Adolesc Psychiatry. 1998;37(10):1041-8. 
82. Straker L, Smith A, Hands B, Olds T, Abbott R. Screen-based media use clusters are related to other activity behaviours and health indicators in adolescents. BMC Public Health. 2013;13:1174.

83. Trinh L, Wong B, Faulkner GE. The independent and interactive associations of screen time and physical activity on mental health, school connectedness and academic achievement among a populationbased sample of youth. J Can Acad Child Adolesc Psychiatry. 2015;24(1): $17-24$.

84. Twenge $\mathbf{J M}$, Joiner TE, Rogers ML, Martin GN. Increases in depressive symptoms, suicide-related outcomes, and suicide rates among US adolescents after 2010 and links to increased new media screen time. Clin Psychol Sci. 2018;6(1):3-17.

85. Whiteley LB, Brown LK, Swenson RR, Romer D, DiClemente RJ, Salazar $L E$, et al. African American adolescents and new media: associations with HIV/STI risk behavior and psychosocial variables. Ethn Dis. 2011; 21(2):216-22.

86. Wu XY, Kirk SFL, Ohinmaa A, Veugelers PJ. The importance of health behaviours in childhood for the development of internalizing disorders during adolescence. BMC Psychology. 2017;5(1):38.

87. Wu X, Bastian K, Ohinmaa A, Veugelers P. Influence of physical activity, sedentary behavior, and diet quality in childhood on the incidence of internalizing and externalizing disorders during adolescence: a population-based cohort study. Ann Epidemiol. 2018; 28(2):86-94.

88. Yan $\mathrm{H}$, Zhang R, Oniffrey TM, Chen G, Wang Y, Wu Y, et al. Associations among Screen Time and Unhealthy Behaviors, Academic Performance, and Well-Being in Chinese Adolescents. Int J Environ Res Public Health. 2017;14(6).

89. Yang F, Helgason AR, Sigfusdottir ID, Kristjansson AL. Electronic screen use and mental well-being of 10-12-year-old children. Eur J Pub Health. 2013; 23(3):492-8.

90. Ybarra ML, Alexander C, Mitchell KJ. Depressive symptomatology, youth internet use, and online interactions: a national survey. J Adolesc Health. 2005;36(1):9-18.

91. McHugh ML. Interrater reliability: the kappa statistic. Biochemia Medica. 2012;22(3):276-82

92. Hinkley T, Teychenne M, Downing KL, Ball K, Salmon J, Hesketh KD. Early childhood physical activity, sedentary behaviors and psychosocial wellbeing: a systematic review. Prev Med. 2014;62:182-92.

93. Wang J, Nansel TR, lannotti RJ. Cyber and traditional bullying: differential association with depression. J Adolesc Health. 2011:48(4):415-7.

94. Feinstein BA, Bhatia $V$, Davila J. Rumination mediates the association between cyber-victimization and depressive symptoms. J Interpers Violence. 2014;29(9):1732-46.

95. Park S. Concentration of internet usage and its relation to exposure to negative content: Does the gender gap differ among adults and adolescents? Women's Studies International Forum. 2009;32(2):98107.

96. Frison E, Eggermont S. Exploring the relationships between different types of Facebook use, perceived online social support, and adolescents' depressed mood. Soc Sci Comput Rev. 2016;34(2):153-71.

97. Thorisdottir IE, Sigurvinsdottir R, Asgeirsdottir BB, Allegrante JP, Sigfusdottir ID. Active and passive social media use and symptoms of anxiety and depressed mood among Icelandic adolescents. Cyberpsychol Behav Soc Netw. 2019;22(8):535-42.

98. Verduyn P, Lee DS, Park J, Shablack H, Orvell A, Bayer J, et al. Passive Facebook usage undermines affective well-being: experimental and longitudinal evidence. J Exp Psychol Gen. 2015;144(2):480.

99. Tortolero SR, Peskin MF, Baumler ER, Cuccaro PM, Elliott MN, Davies SL, et al. Daily violent video game playing and depression in preadolescent youth. Cyberpsychol Behav Soc Netw. 2014;17(9):609-15.

100. Lobel A, Engels RC, Stone LL, Burk WJ, Granic I. Video gaming and children's psychosocial wellbeing: a longitudinal study. J Youth Adolesc. 2017;46(4): 884-97.

101. Granic I, Lobel A, Engels RC. The benefits of playing video games. Am Psychol. 2014;69(1):66.

102. Russoniello CV, O'Brien K, Parks JM. EEG, HRV and psychological correlates while playing bejeweled II: a randomized controlled study. Annu Rev Cyberther Telemed. 2009;7(1):189-92.

103. Fish MT. A randomized controlled study of the effectiveness of casual video games in reducing symptoms of anxiety; 2011
104. Li J, Theng Y-L, Foo S. Game-based digital interventions for depression therapy: a systematic review and meta-analysis. Cyberpsychol Behav Soc Netw. 2014;17(8):519-27.

105. Cooper AR, Goodman A, Page AS, Sherar LB, Esliger DW, van Sluijs EM, et al. Objectively measured physical activity and sedentary time in youth: the international children's accelerometry database (ICAD). Int J Behav Nutr Phys Act. 2015;12(1):113.

106. Dunton GF, Yang C-H, Zink J, Dzubur E, Belcher BR. Longitudinal changes in Children's accelerometer-derived activity pattern metrics. Med Sci Sports Exerc. 2019.

107. Hankin BL. Development of sex differences in depressive and co-occurring anxious symptoms during adolescence: descriptive trajectories and potential explanations in a multiwave prospective study. J Clin Child Adolesc Psychol. 2009;38(4):460-72.

108. Alloy LB, Hamilton JL, Hamlat EJ, Abramson LY. Pubertal development, emotion regulatory styles, and the emergence of sex differences in internalizing disorders and symptoms in adolescence. Clin Psychol Sci. 2016; 4(5):867-81

109. Hyde JS, Mezulis AH, Abramson LY. The ABCs of depression: integrating affective, biological, and cognitive models to explain the emergence of the gender difference in depression. Psychol Rev. 2008; 115(2):291-313.

110. Papadakis AA, Prince RP, Jones NP, Strauman TJ. Self-regulation, rumination, and vulnerability to depression in adolescent girls. Dev Psychopathol. 2006; 18(3):815-29.

111. Houghton S, Hunter SC, Rosenberg M, Wood L, Zadow C, Martin K, et al. Virtually impossible: limiting Australian children and adolescents daily screen based media use. BMC Public Health. 2015;15:5.

112. Nesi J, Prinstein MJ. Using social Media for Social Comparison and Feedback-Seeking: gender and popularity moderate associations with depressive symptoms. J Abnorm Child Psychol. 2015;43(8): 1427-38.

113. Liao Y, Intille S, Wolch J, Pentz MA, Dunton GF. Understanding the physical and social contexts of children's nonschool sedentary behavior: an ecological momentary assessment study. J Phys Act Health. 2014; 11(3):588-95.

114. Marques A, Sallis JF, Martins J, Diniz J, Carreiro Da Costa F. Correlates of urban children's leisure-time physical activity and sedentary behaviors during school days. Am J Hum Biol. 2014;26(3):407-12.

115. Kiluk BD, Weden S, Culotta VP. Sport participation and anxiety in children with ADHD. J Atten Disord. 2009;12(6):499-506.

116. Babiss LA, Gangwisch JE. Sports participation as a protective factor against depression and suicidal ideation in adolescents as mediated by self-esteem and social support. J Dev Behav Pediatr. 2009;30(5): 376-84.

117. Greenspan SB, Griffith C, Murtagh EF. LGBTQ youths' school athletic experiences: a 40-year content analysis in nine flagship journals. J LGBT Issues Couns. 2017;11(3):190-200.

118. Gawrilow C, Stadler G, Langguth N, Naumann A, Boeck A. Physical activity, affect, and cognition in children with symptoms of ADHD. J Atten Disord. 2016:20(2):151-62

119. Carter T, Morres ID, Meade O, Callaghan P. The effect of exercise on depressive symptoms in adolescents: a systematic review and meta-analysis. J Am Acad Child Adolesc Psychiatry. 2016;55(7):580-90.

120. Alberga AS, Sigal RJ, Sweet SN, Doucette S, Russell-Mayhew S, Tulloch $\mathrm{H}$, et al. Understanding low adherence to an exercise program for adolescents with obesity: the HEARTY trial. Obes Sci Pract. 2019;5(5): 437-48.

121. Gunnell KE, Flament MF, Buchholz A, Henderson KA, Obeid N, Schubert N, et al. Examining the bidirectional relationship between physical activity, screen time, and symptoms of anxiety and depression over time during adolescence. Prev Med. 2016;88:147-52.

122. Omorou AY, Langlois J, Lecomte E, Briancon S, Vuillemin A. Cumulative and bidirectional association of physical activity and sedentary behaviour with health-related quality of life in adolescents. Qual Life Res. 2016:25(5):1169-78.

123. Shiffman S, Stone AA, Hufford MR. Ecological momentary assessment. Annu Rev Clin Psychol. 2008:4:1-32.

124. Greaves-Lord K, Ferdinand RF, Sondeijker FE, Dietrich A, Oldehinkel AJ, Rosmalen JG, et al. Testing the tripartite model in young adolescents: is 
hyperarousal specific for anxiety and not depression? J Affect Disord. 2007; 102(1-3):55-63.

125. Zink J, Belcher BR, Kechter A, Stone MD, Leventhal AM. Reciprocal associations between screen time and emotional disorder symptoms during adolescence. Prev Med Rep. 2019;13:281-8.

126. Ryu S, Kim H, Kang M, Pedisic Z, Loprinzi PD. Secular trends in sedentary behavior among high school students in the United States, 2003 to 2015. Am . Health Promot. 2019;33(8):1174-81. https://doi.org/10.1177/0890117119854043.

127. Yang L, Cao C, Kantor ED, Nguyen LH, Zheng X, Park Y, et al. Trends in sedentary behavior among the US population, 2001-2016. Jama. 2019; 321(16):1587-97.

\section{Publisher's Note}

Springer Nature remains neutral with regard to jurisdictional claims in published maps and institutional affiliations.

Ready to submit your research? Choose BMC and benefit from:

- fast, convenient online submission

- thorough peer review by experienced researchers in your field

- rapid publication on acceptance

- support for research data, including large and complex data types

- gold Open Access which fosters wider collaboration and increased citations

- maximum visibility for your research: over $100 \mathrm{M}$ website views per year

At BMC, research is always in progress.

Learn more biomedcentral.com/submissions 